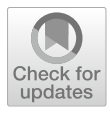

Cite as

Nano-Micro Lett.

(2020) 12:156

Received: 7 May 2020

Accepted: 27 June 2020

Published online: 31 July 2020

(C) The Author(s) 2020

\section{Hot-Casting Large-Grain Perovskite Film for Efficient Solar Cells: Film Formation and Device Performance}

\author{
Kejun Liao ${ }^{1}$, Chengbo $\mathrm{Li}^{1}$, Lisha Xie ${ }^{1}$, Yuan Yuan ${ }^{1}$, Shurong Wang ${ }^{1}$, Zhiyuan Cao ${ }^{1}$, \\ Liming Ding ${ }^{2 凶}$, Feng $\mathrm{Hao}^{1 凶}$ \\ $\bowtie$ Liming Ding, ding@nanoctr.cn; Feng Hao, haofeng@uestc.edu.cn \\ 1 School of Materials and Energy, University of Electronic Science and Technology of China, \\ Chengdu 610054, People's Republic of China \\ 2 Center for Excellence in Nanoscience (CAS), Key Laboratory of Nanosystem and Hierarchical Fabrication \\ (CAS), National Center for Nanoscience and Technology, Beijing 100190, People's Republic of China
}

\title{
HIGHLIGHTS
}

- Recent advances of a hot-casting technique used to deposit high-quality perovskite films are reviewed.

- Perovskite films with large grain size, uniform thickness, and preferred crystalline orientation are deposited.

- Future perspectives on the upscaling of perovskite solar cell are described.

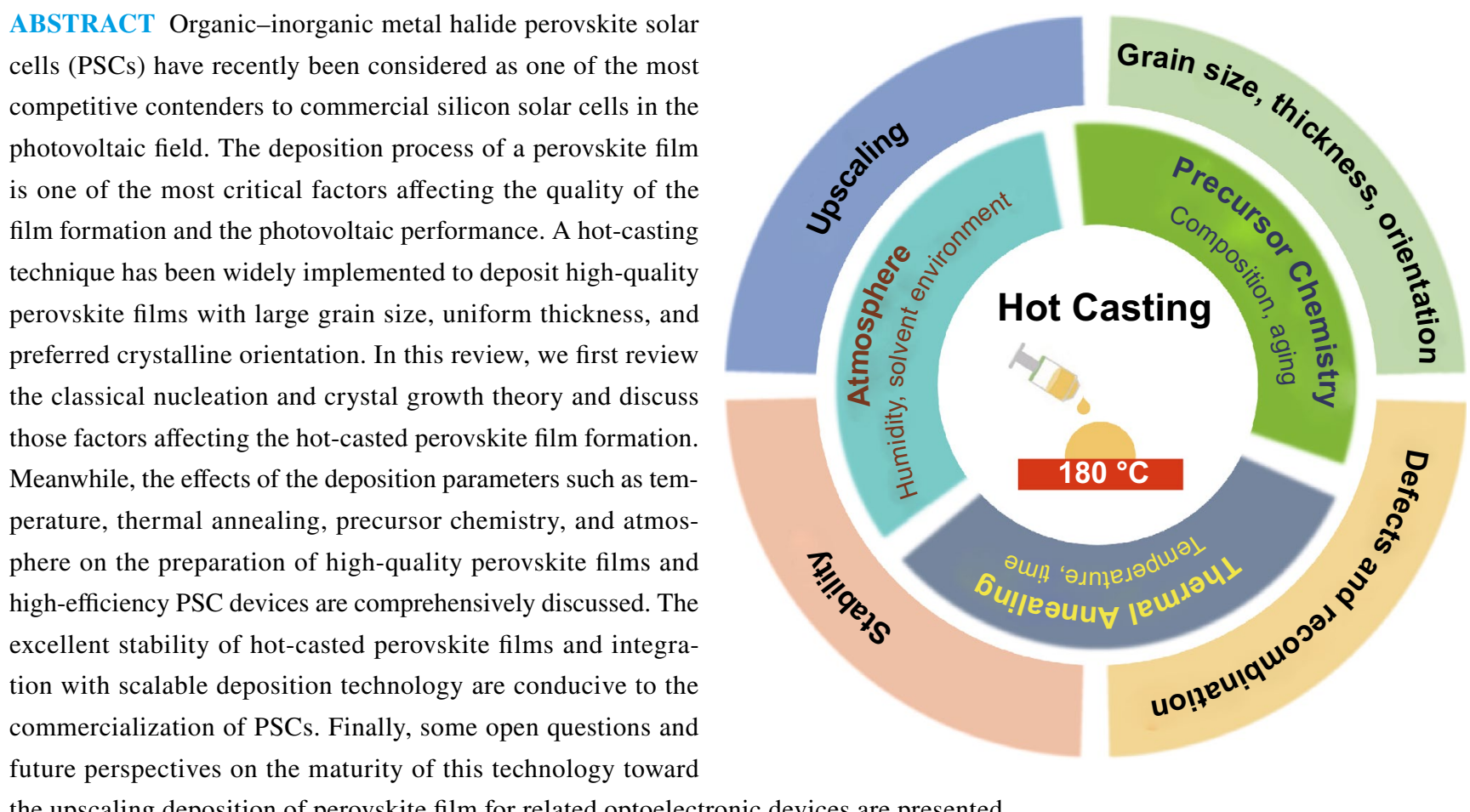
the upscaling deposition of perovskite film for related optoelectronic devices are presented.

KEYWORDS Perovskite film; Hot-casting; Temperature; Precursor chemistry; Grain size 


\section{Introduction}

The development of low-cost and high-efficiency solar cells has attracted interest worldwide from both the academy and industry. Organic-inorganic lead halide perovskite has recently emerged as an efficient light-absorbing layer in photovoltaic applications with unique properties including a high absorption coefficient, tunable bandgap, and solution processing capability [1-8]. The improvement in the power conversion efficiency (PCE) of perovskite solar cells (PSCs) is mainly due to the effective control of the film morphology and the interfacial defect passivation. Therefore, the choice of deposition technique is particularly important. One-step spin coating [9-12], sequential deposition [13], two-step spin coating $[14,15]$, and vapor deposition $[2,16]$ have been widely used to deposit high-quality perovskite films. Despite being fairly complicated, sequential deposition and two-step spin coating exhibit good repeatability and high controllability. Vapor deposition is suitable for planar devices with a high film uniformity, although deposition under a strong vacuum is expensive. Crystallization in a conventional one-step spin coating is difficult to control because the deposition environment such as the humidity and temperature seriously affects the repeatability, and the thermal annealing process involves evaporation of the solvent and volatilization of the organic components.

Hot-casting technology has recently been developed in the deposition of high-quality perovskite thin films with notable advantages, such as a rapid crystallization, short film formation process, large increase in the grain size, preferred crystalline orientation, and low defect states [17-19]. A direct formation mechanism has been proposed within the framework of nucleation growth theory [20]. A high substrate temperature provides the necessary driving force for the phase change, resulting in an ultrashort crystallization process. Meanwhile, sufficient thermal energy also facilitates the diffusion of atoms in a liquid without the formation of an intermediate phase. Nie et al. first reported this methodology and further improved the film quality by optimizing the deposition parameters, such as the substrate temperature $[19,21]$, annealing temperature [22], and precursor composition [11]. This technology has recently been extended to the deposition of a variety of perovskite films, including organic-inorganic hybrid, all-inorganic, lead-free, and lowdimensional perovskite films [23-25].
In this review, the recent developments and advances of the hot-casting deposition of perovskite films are comprehensively summarized and discussed from the perspective of film quality, defects, carrier recombination, and stability. First, classic nucleation and crystal growth theory are revisited. The effects of different deposition parameters in a hot-casting technique, including the substrate temperature, thermal annealing, precursor chemistry, and atmosphere, are further discussed. Next, the advantages of this promising technology are discussed in terms of grain size, uniform thickness, and preferred crystalline orientation. The implementation of this technology in different types of perovskite film deposition has also been reviewed. Finally, some open questions and future perspectives regarding the maturity of this technology toward the upscaled manufacturing of perovskite-related optoelectronic devices are presented.

\section{Hot-Casting Technology}

\subsection{Fundamentals of Nucleation and Crystal Growth}

Classic nucleation and the crystal growth mechanism are first revisited [26-28]. Figure 1a describes a schematic illustration of a hot-casting process for perovskite film deposition. The hot-casting technology aims to spin coat a hot precursor solution on a substrate maintained at higher temperature. Factors such as the substrate temperature, solution concentration, solvent, and supersaturated environment affect crystal growth. These deposition parameters are comprehensively discussed and correlated with the processes of nucleation and growth, as indicated in a LaMer diagram.

\subsubsection{Classical Nucleation and Classical Growth}

There are three classic nucleation and growth models of thin films, including the Volmer-Weber model, Frank-van der Merwe model, and Stranski-Krastanov model [30-33]. For the nucleation and growth of most polycrystalline thin films, the Volmer-Weber model is valid if the substrate temperature is sufficiently high and the deposited atoms have a certain diffusion capability. Therefore, our discussion is based on the Volmer-Weber model for hot casting process with unique film-forming characteristics. In classical nucleation theory, the solution must be in a 
(a)
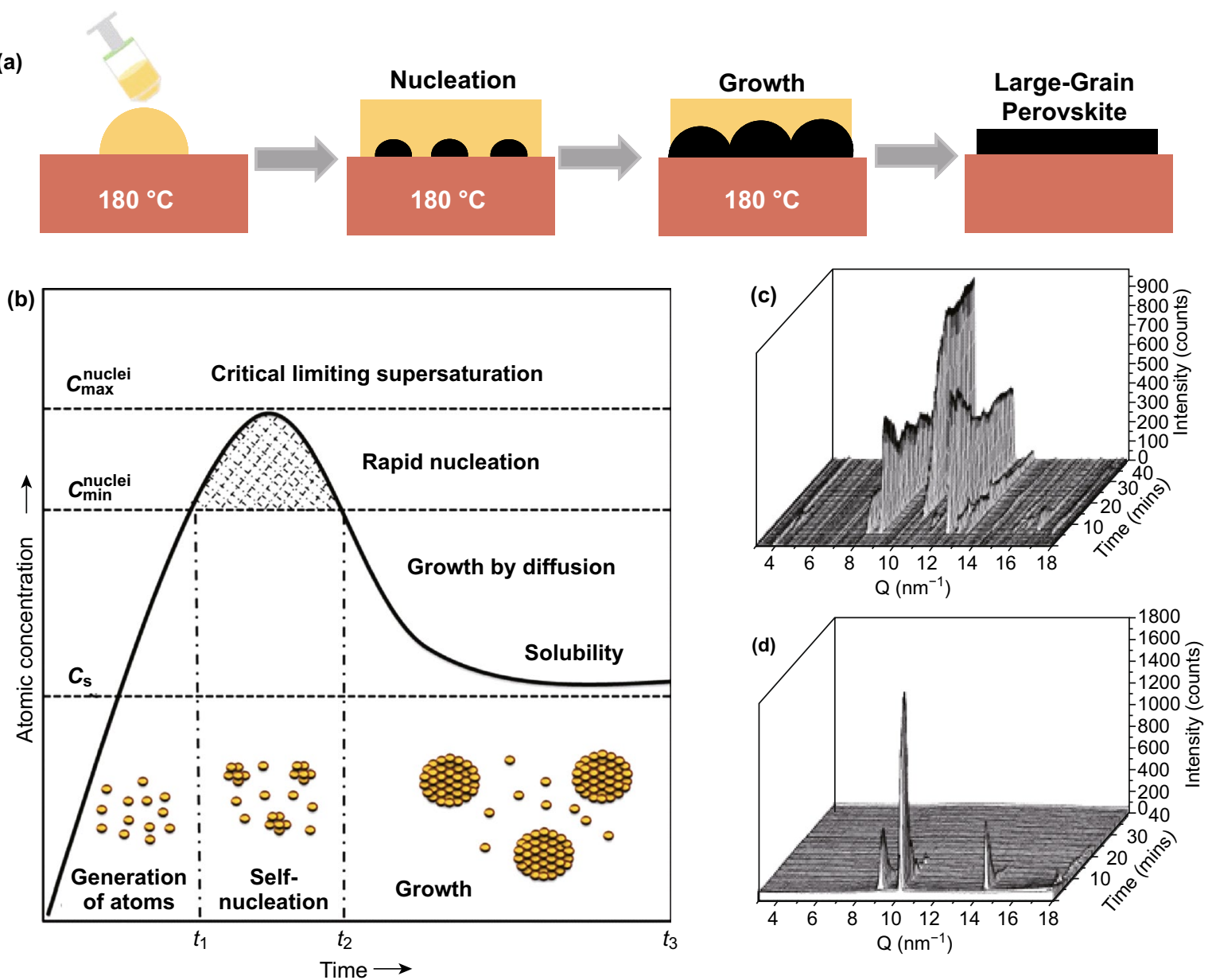

Fig. 1 a Schematic illustration of the hot-casting process. b LaMer diagram for crystallite formation stages in a solution [29]. Copyright $\odot$ 1950 American Chemical Society. c Time-dependent grazing-incidence wide-angle X-ray scattering (GIWAXS) profiles of the perovskite film drop cast on the $70{ }^{\circ} \mathrm{C}$ substrate and $\mathbf{d ~} 180{ }^{\circ} \mathrm{C}$ substrate from a solution to a solid state (0-40 min) [20]. Copyright $\odot 2016$ American Chemical Society

supersaturated state to initiate crystallization. Nucleation with preferential nucleation sites is called a heterogeneous nucleation, which means that new phases are preferentially formed within certain regions of a liquid phase. During the process of thermodynamic nucleation, the system needs to overcome an energy barrier, which is the maximum free energy of critical nucleation $\left(\Delta G^{*}\right)$.

$\Delta G^{*}=\frac{16 \pi \sigma^{3}}{3 \Delta G_{v}}$

where $\sigma$ is the interface free energy, and $\Delta G_{v}$ is the bulk free energy. Formation of nuclei in solution is closely related to the critical radius $\left(r^{*}\right)$ : $r^{*}=\frac{2 \sigma}{\Delta G_{v}}$

when $r<r^{*}$, the crystal nucleus is unstable; when $r=r^{*}$, the crystal nucleus is in a metastable state; when $r>r^{*}$, it is converted into a stable crystal nucleus and large nucleation begins. Therefore, $r^{*}$ represents a critical value for the transition from an unstable crystal nucleus to a stable crystal nucleus, i.e., $r^{*}$ represents the minimum size at which the particles are further grown in a solution without being dissolved. 


\subsubsection{LaMer Mechanism}

According to the typical concentration distribution curve in the LaMer diagram shown in Fig. 1b, the process of nucleation and growth can be divided into three stages, i.e., regions I, II, and III, representing the prenucleation, nucleation, and growth stages, respectively. In LaMer mode, the level of atomic concentration is the direct control factor for generating the crystal nuclei and achieving the particle size growth. Here, $C_{\mathrm{s}}$ is the solubility limit of the solution, $C_{\mathrm{c}}$ is the critical concentration of the solution, and $C_{\mathrm{m}}$ is the maximum supersaturation. In the $0-t_{1}$ segment, the centrifugal force and substrate temperature promote the solvent evaporation and increase the solution concentration of precursor until reaching $C_{\mathrm{s}}$, although no obvious nucleation occurs at this point. The deposition temperature, precursor solution concentration, deposition rate, and solvent composition will affect the prenucleation stage. In the $t_{1}-t_{2}$ segment, the concentration of the solution reaches the critical level of nucleation, and the nucleation radius is larger than $r^{*}$. The nucleation is transformed into a stable crystal nucleus, and a stable heterogeneous nucleus is formed at the beginning of slow nucleation. After the precursor solution is dropped onto the substrate, when the binding energy between the crystal nucleus and the adsorption atom is higher than the binding energy between the adsorption atom and the substrate, the crystal nucleus is more likely to form islands in combination with the diffusion-migrating atom. During the nucleation stage of the hot-casting process, a high substrate temperature, a diffusion capacity of the deposited atoms, and wettability between the deposited material and the substrate are essential requirements. Simultaneously, the precursor chemistry such as the solution aging time, solution composition, and solvent selection are important factors. The nucleation rate in $t_{2}-t_{3}$ segment is rapidly increasing. Secondary nucleation occurs in an irregular channel. The distance between the islands gradually decreases and merges into a large island or forms a continuous film. At this stage, the solution concentration is closely related to the nucleation and growth rate. The balance of the nucleation and growth rate effectively improves the film coverage [34]. When the solution concentration is below the critical supersaturation, nucleation stops owing to a low concentration of the solution [35]. The thermal annealing facilitate a fine control of the volatilization of the components and solvents, and ultimately a high-quality perovskite film is obtained.

\subsection{Temperature and Thermal Annealing}

\subsubsection{Direct Formation Mechanism}

The substrate temperature and thermal annealing play crucial roles in nucleation growth. When the substrate temperature is relatively low (less than $100{ }^{\circ} \mathrm{C}$ ), the perovskite film formation process is divided into three stages: the initial solution stage, the transition-to-solid film stage, and the transformation stage from intermediates into a perovskite film [36]. However, when the substrate temperature is increased $\left(100-180{ }^{\circ} \mathrm{C}\right)$, the formation of the perovskite film adopts a direct formation mechanism [20]. Figure 1c, d shows in situ grazing-incidence wide-angle X-ray scattering (GIWAXS) curves of perovskite from the precursor solution to the perovskite film at different substrate temperatures of 70 and $180{ }^{\circ} \mathrm{C}$, respectively. The X-ray data are acquired after a regular time interval, and the time coordinate (right) represents the characteristic peak obtained within each frame interval. The peak of the scattering vector $(Q)$ at $\sim 4,8$, and $8.7 \mathrm{~nm}^{-1}$ is attributed to the $\mathrm{PbI}_{2}$-solvent complex. The peak at $Q=12.0 \mathrm{~nm}^{-1}$ is assigned to the intermediate-stage $\mathrm{MAPbCl}_{3}$-solvent complex, whereas the peak at $Q=10.2 \mathrm{~nm}^{-1}$ is due to the perovskite stage. The intermediate $\mathrm{MAPbCl}_{3}$ and $\mathrm{PbI}_{2}$-solvent complex was not seen in the film grown at $180{ }^{\circ} \mathrm{C}$. This indicates that there is no intermediate phase formation during the hot-casting process, since sufficient thermal energy is provided to accelerate the reactant diffusion and interaction.

\subsubsection{Substrate Temperature}

The substrate temperature affects the nucleation rate and film morphology by changing the supersaturation of the solution. Nie et al. first reported a strong correlation between the substrate temperature and grain size during a hot-casting process (Fig. 2a), as well as the mobility and final PCE (Fig. 2b-d). When the substrate temperature is higher than the crystallization temperature of the perovskite phase, the high boiling solvent promotes a stable growth of the perovskite crystal with large crystal grains. When the substrate temperature is increased to $180^{\circ} \mathrm{C}$, a grain size of $180 \mu \mathrm{m}$ and charge mobility of $20 \mathrm{~cm}^{2} \mathrm{~V}^{-1} \mathrm{~s}^{-1}$ are obtained in the perovskite film. A large-grain perovskite film improves the device performance in two ways, reducing the crystal 

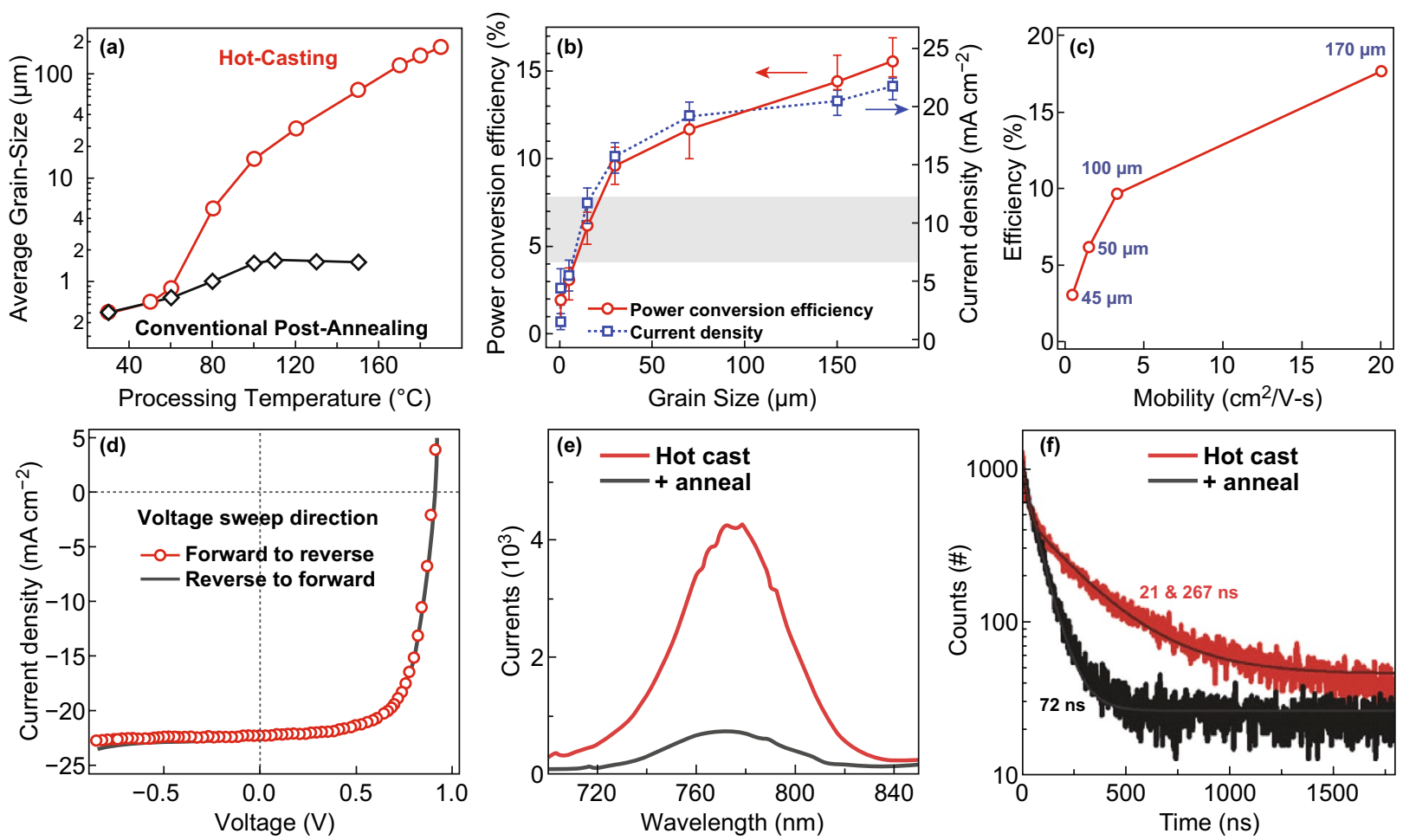

Fig. 2 a Comparison of grain size as a function of the processing temperature. b Average overall PCE (left) and $J_{\text {sc }}$ (right) as a function of crystalline grain size. $\mathbf{c}$ PCE values are correlated with the bulk mobility of the perovskite layer (the labels correspond to the average grain size). $\mathbf{d}$ Average $J-V$ characteristics resulted by sweeping the voltage from forward to reverse bias and from reverse to forward bias [19]. Copyright $(9$ 2017 American Association for the Advancement of Science. e PL and f TRPL spectra of unannealed and annealed perovskites [22]. Copyright (C) 2016 WILEY-VCH Verlag GmbH \& Co. KGaA, Weinheim

interface and lowering the defect density, thus increasing the mobility and suppressing the charge trapping [19].

\subsubsection{Thermal Annealing}

Yang et al. further described the Volmer-Weber growth mechanism for the formation of island-like grains and the transition to a dense perovskite film in a hot-casting process [37]. The thermal energy plays a key role in accelerating the crystallization of perovskite and the diffusion of the precursor, which directly determines the film morphology (Fig. 1b). For instance, the thermal energy can reduce the surface tension between the precursor solution and the substrate, thus enhancing the tendency to form large islands with reduced surface defects (such as vacancies, dislocations, and grain boundaries). As the temperature further increases, it was observed that isolated islands grow and begin to form bonds with each other, eventually forming a high-quality perovskite film without pinholes. Thermal annealing not only promotes the solvent evaporation and accelerates the material transport within the film, but also improves the charge transport in the perovskite film. Janssen et al. characterized the annealing procedure using in situ photoluminescence spectroscopy [22]. The thermal annealing of the perovskite layer on poly(3,4-ethylenedioxythiophene)/poly(styrenesulfonate) (PEDOT:PSS) affects the photoluminescence properties, as shown in Fig. 2e, f. The luminescence intensity after annealing was 7 times lower than that of the as-cast film, and the photoluminescence lifetime (72 ns for a single-index fit) was significantly shorter than that of the as-cast film (double exponential lifetime of 21 and $267 \mathrm{~ns}$ ). This difference was due to the increased charge carrier mobility or fewer defects in the annealed film. However, if the annealing temperature is too high and the annealing time is too long, it will promote the decomposition of the perovskite and eventually damage the photovoltaic performance. Ma et al. investigated the relationship between the thermal annealing and orientation of hot-casted $\mathrm{PEA}_{2} \mathrm{MA}_{2} \mathrm{~Pb}_{3} \mathrm{I}_{10}$ films [38]. Nateghi et al. also reported that 
the changes in annealing temperature and substrate temperature affect the morphology of the deposited film [39]. Flash infrared annealing (FIRA) can promote the formation and crystallization of perovskite films through rapid solvent removal. Compared to conventional thermal annealing, short heating pulses can significantly reduce the degradation of organic components even at an extremely high temperature $[40,41]$. Ren et al. found that the grain size distribution at the edge of the perovskite film prepared using hot casting is larger than the central size distribution and the particle size distribution is annular [42]. It is believed that a compensation flow from the center of the solution to the edge naturally occurs during the evaporation of the solvent, thus resulting in a higher concentration and larger grain size at the edges.

\subsection{Precursor Chemistry}

\subsubsection{Additives}

The perovskite precursor has a strong impact on the film morphology and device performance, such as the composition [43, 44], concentration [45], solution aging time [46], and solvent selection [47]. A poorly soluble inorganic lead salt requires the selection of strongly polar aprotic organic solvents. The boiling point and vapor pressure of the solvent determine the rate of solution evaporation. The viscosity of the solvent affects the substrate wettability and thus the film formation [48]. In addition, the Lewis-based nature of some high polar aprotic organic solvents can induce a solvent-solute coordination to modulate the crystallization process. Therefore, the solvation ability plays a key role in determining the perovskite crystallization process [49]. The perovskite precursor solution is regarded as a colloidal cluster with a soft colloidal skeleton, and several coordination complexes constitute the colloidal skeleton. The size of the colloidal clusters is controlled by additives $\left(\mathrm{Cl}^{-}\right.$and $\left.\mathrm{Br}^{-}\right)$[50]. Liao et al. reported that the incorporation of chlorine can improve the optoelectronic properties and environmental stability of perovskite films. The incorporation of $10 \mathrm{wt} \% \mathrm{Cl}^{-}$into a $\mathrm{MAPbI}_{3}$ precursor solution significantly improves the film uniformity and coverage. An X-ray diffraction (XRD) pattern showed that increasing the chlorine amount induces a significant increase of the scattering intensity of the (110) plane, whereas the intensity of the (020) plane is decreased, indicating a promoted orientation in the direction of the (110) plane. The orientation is highly dependent on the halide distribution during the hot-casting process. The solvent evaporates instantly upon contact with the hot substrates and draws the preaggregated $\mathrm{Cl}^{-}$-rich domains toward the surfaces. $\mathrm{Cl}^{-}$preferentially distributes closer to the $\mathrm{TiO}_{2}$ substrates, and the included $\mathrm{Cl}^{-}$precursors tend to naturally aggregate owing to a lower solubility. Consequently, the rapid crystallization creates a gradient halide distribution as well as morphological changes. A high nucleation density and grain coarsening are further induced. A longer time-resolved photoluminescence (TRPL) lifetime was observed in a perovskite film with added chloride ions (Fig. 3a, b). Improvements in the device performance have been ascribed to the improved uniformity of the perovskite film, good orientation of the perovskite crystals, and a longer carrier diffusion length. Wu et al. reported that $\mathrm{Cl}^{-}$can improve the film morphology by retarding the crystallization rate, whereas $\mathrm{Br}^{-}$can improve the open-circuit voltage $\left(V_{\mathrm{oc}}\right)$ of the corresponding devices and stabilize the perovskite lattice [51]. Hao et al. reported that a slight excess of methylammonium iodide (MAI) in the precursor solution can compensate for the MAI loss owing to the high substrate temperature [52]. Significant increases in the grain size and crystallinity of the MAI-rich perovskite films were observed. Chen et al. further tuned the thickness of the perovskite layer within the range of $700-1600 \mathrm{~nm}$ by adjusting the substrate temperature $\left(25-100{ }^{\circ} \mathrm{C}\right)$ and the precursor concentration (1-2 M) [53]. Figure 3c, d shows the UV-Vis absorption and external quantum efficiency (EQE) spectra for the corresponding devices. Within the long-wavelength range, the absorption was enhanced from 25 to $70{ }^{\circ} \mathrm{C}$, thereby contributing to enhanced light-harvesting and improved $J_{\text {sc }}$ values. The photoluminescence (PL) intensity of a sample at $70{ }^{\circ} \mathrm{C}$ is much higher than that at $25^{\circ} \mathrm{C}$, indicating fewer trap states in the former. Gong et al. further used an ultrahigh-temperature substrate $\left(\sim 240^{\circ} \mathrm{C}\right)$ to deposit a perovskite film in a short time owing to the rapid evaporation of the solvent [54].

\subsubsection{Aging Time and Solvent}

The aging time of the precursor solution can affect the size and structure of the colloidal clusters, as well as the resultant 

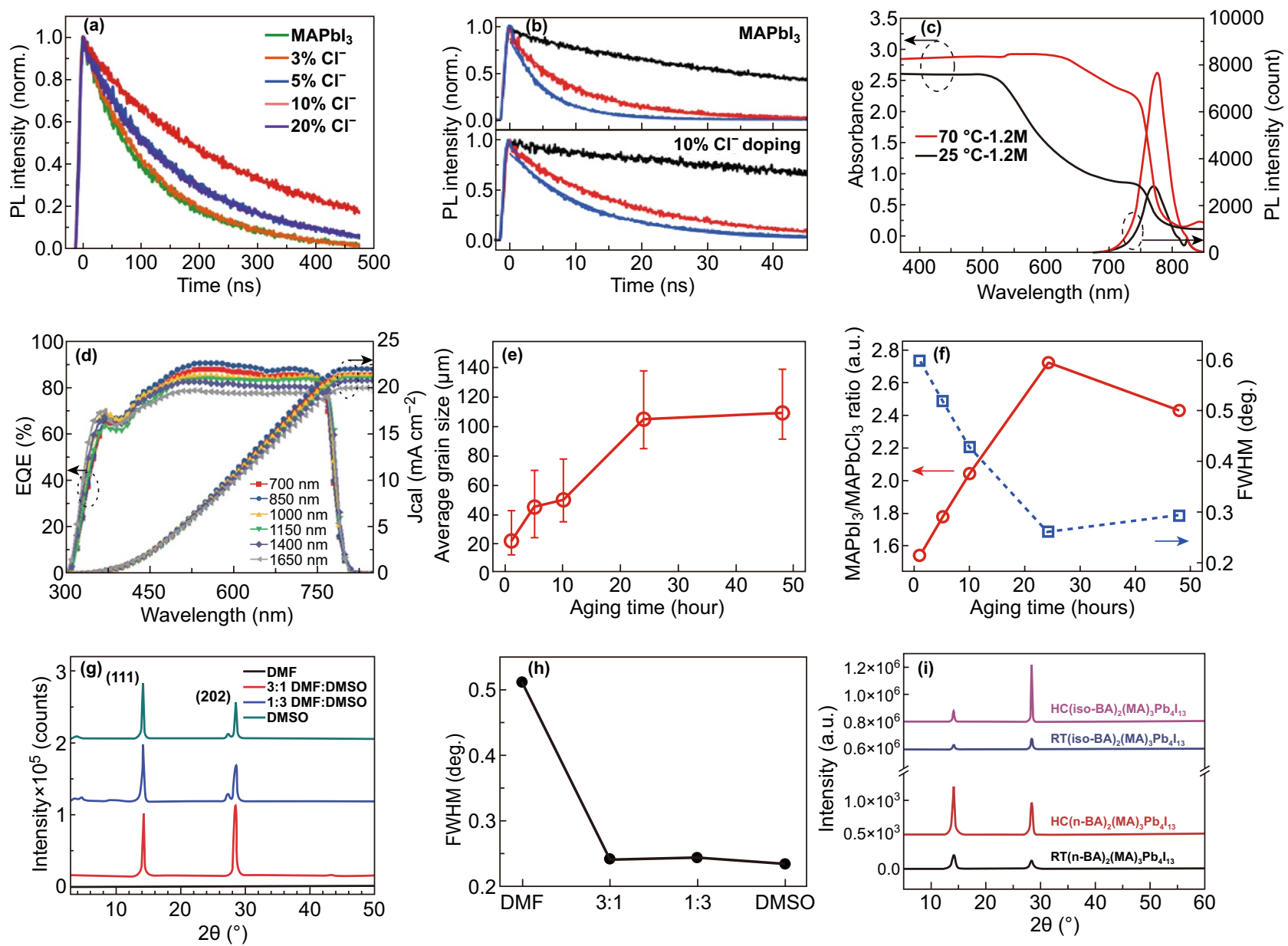

Fig. 3 a TRPL curves for a pristine perovskite film and with different chlorine contents. b TRPL curves for pristine perovskite films (black) in conjunction with a hole quencher (red) and an electron quencher (blue) [11]. Copyright @ 2016 WILEY-VCH Verlag GmbH \& Co. KGaA, Weinheim. c Absorption spectra and steady-state PL emission spectra of $\mathrm{MAPbI}_{3}$ perovskite films fabricated at different casting temperatures of $25{ }^{\circ} \mathrm{C}$ and $70{ }^{\circ} \mathrm{C}$. d EQE spectra for perovskite solar cells with varying active layer thicknesses through hot cast [53]. Copyright $\odot$ 2016 WILEY-VCH Verlag GmbH \& Co. KGaA, Weinheim. e Average grain size with error bar determined for 1-48 h aging time. f Peak ratio of $\mathrm{MAPbI}_{3} / \mathrm{MAPbCl}_{3}$ as a function of aging time and $\mathrm{FWHM}$ of $\mathrm{MAPbI}_{3}$ peak $\left(2 \theta=14.28^{\circ}\right)$ [46]. Copyright $(2) 2017$ WILEY-VCH Verlag GmbH $\&$ Co. KGaA, Weinheim. $\mathrm{g}$ XRD patterns as a function of peak intensity versus $2 \theta$ (degree) of the hot-cast $\mathrm{BA}_{2} \mathrm{MA}_{4} \mathrm{~Pb}_{5} \mathrm{I}_{16}$ films from precursor solutions using DMF, DMSO, and mixed solvents. h FWHM of the (111) reflection as a function of precursor solvent used for thinfilm fabrication [17]. Copyright (C) 2017 WILEY-VCH Verlag GmbH \& Co. KGaA, Weinheim. i XRD patterns of RT and hot-cast fabricated $(\mathrm{n}-\mathrm{BA})_{2}(\mathrm{MA})_{3} \mathrm{~Pb}_{4} \mathrm{I}_{13}$ and (iso-BA) $)_{2}(\mathrm{MA})_{3} \mathrm{~Pb}_{4} \mathrm{I}_{13}$ perovskites [18]. Copyright (C) 2019 Elsevier Ltd.

nucleation and growth process. Mohite et al. reported a strong correlation between the aging time and film crystallinity [46]. The results showed that the crystallinity and grain size of perovskite films were significantly improved when the aging time of the precursor solution exceeds $24 \mathrm{~h}$. Figure 3e shows the average grain size as a function of the solution of aging time. Along with the grain size growth, the XRD peak ratio of the $\mathrm{MAPbI}_{3} / \mathrm{MAPbCl}_{3}$ film increased to 2.73 when the solution aging time reached $24 \mathrm{~h}$ (Fig. 3f). The full width at half maximum (FWHM) of the peak of $\mathrm{MAPbI}_{3}$ at $14.28^{\circ}(110)$ exhibits an increase in the crystalline quality as the aging time increases to a certain value. As the precursor solution ages, it gradually forms large seeds (or crystals). The precursor aging has also been proven to significantly affect the grain growth, phase purity, surface uniformity, and trap state density of the perovskite film. Meanwhile, adjusting the solvents and composition of the precursor has a vital role in the phase formation and crystalline properties of the perovskite films. A $\mathrm{BA}_{2} \mathrm{MA}_{4} \mathrm{~Pb}_{5} \mathrm{I}_{16}$ film deposited using a $N, N$-dimethylformamide (DMF)/dimethyl sulfoxide (DMSO) mixed solvent showed a strong preferential orientation, in which the (111) diffraction intensity was 
about tenfold higher than that prepared with a DMF solvent (Fig. 3g) [17]. When the DMSO ratio increased, the FWHM of the (111) peak further decreased from $0.51^{\circ}$ to $0.24^{\circ}$ (Fig. 3h). Wang et al. used gamma-butyrolactone (GBL) and DMF co-solvents to deposit perovskite films. It was reported that the grain size and photovoltaic parameters of the device from the GBL solvent were significantly lower than those from the DMF solvent [55]. In addition, Iyer et al. regulated the perovskite crystallization and grain growth with DMSO as a Lewis base adduct [56].

\subsubsection{Composition and Other Factors}

The perovskite film morphology can be further tuned through the processing parameters, such as the substrate temperature, rotating speed, and thermal annealing. These processing parameters affect the solute diffusion and perovskite crystallization behavior through the thermal energy and centrifugal force. Thermal annealing promotes evaporation of the remaining organic residue. As shown in Fig. 3i, the main diffraction peaks of (n-BA) $)_{2}(\mathrm{MA})_{3} \mathrm{~Pb}_{4} \mathrm{I}_{13}$ and (iso$\mathrm{BA})_{2}(\mathrm{MA})_{3} \mathrm{~Pb}_{4} \mathrm{I}_{13}$ films at $14.10^{\circ}$ and $28.37^{\circ}$ represent the (111) and (202) crystallographic planes. Compared with the diffraction peak of the hot-casted (n-BA) ${ }_{2}(\mathrm{MA})_{3} \mathrm{~Pb}_{4} \mathrm{I}_{13}$ perovskite film, the diffraction intensities of (iso$\mathrm{BA})_{2}(\mathrm{MA})_{3} \mathrm{~Pb}_{4} \mathrm{I}_{13}$ were higher and narrower, which indicates that the branched-chain spacers improved the crystallization of the two-dimensional (2D) perovskites compared to the linear chain counterparts. In addition, the change in the diffraction intensity ratio between (111) and (202) of the hot-casted (iso-BA) ${ }_{2}(\mathrm{MA})_{3} \mathrm{~Pb}_{4} \mathrm{I}_{13}$ film implies that the crystal orientation of the film changed substantially [18]. Moon et al. used MAI and lead acetate $\left(\mathrm{PbAc}_{2}\right)$ as precursors to form a high-quality perovskite layer [57]. The $\mathrm{PbAc}_{2}$ residue can be conveniently removed through by-product gas ( $\left.3 \mathrm{MAI}+\mathrm{PbAc}_{2} \rightarrow \mathrm{MAPbI}_{3}+2 \mathrm{MAAc}\right)$ to accelerate the crystal growth to form a fully covered, pinhole-free, and highly crystalline perovskite film. Janssen et al. prepared a high-quality perovskite layer from a mixture of $\mathrm{PbAc}_{2}$, $\mathrm{PbI}$, and MAI [22]. Huang et al. reported the use of methylammonium acetate (MAAc) as a general solvent to deposit high-quality perovskite films in an ambient environment. A constant substrate temperature $\left(100{ }^{\circ} \mathrm{C}\right)$ was applied to promote solvent evaporation, resulting in supersaturation, and a rapid nucleation and crystal growth [58].

\subsection{Atmosphere}

Different deposition conditions affect the crystallinity and surface morphology of as-cast perovskite films [59]. As one advantage of the hot-casting technology, the deposition is not sensitive to the processing environment; in other words, perovskite films can be deposited in ambient air, and the device shows excellent humidity stability [60-63]. Mori et al. prepared $\mathrm{MAPbI}_{3}$ films under ambient conditions (relative humidity $=42-48 \%$ ) by combining a gas flow with hot-casting technology [64]. Owing to the difference in the centrifugal force between the center and edge of the substrate, the flowing gas can significantly accelerate the mass transfer and eliminate the nonuniformity of its thickness. Eslamian et al. prepared $\mathrm{MAPbI}_{3}$ perovskite films using a two-step sequential deposition method [65]. To achieve full coverage, $\mathrm{PbI}_{2}$ solution with a low concentration was first sprayed onto a heated substrate as the substrate temperature neared the boiling point of the DMF solvent $\left(153^{\circ} \mathrm{C}\right)$. The deposition of thick $\mathrm{PbI}_{2}$ films by high-temperature spraying is more conducive to the deposition of thicker perovskite films than a conventional method applied at RT. Aguiar et al. found that in situ exposure to water vapor reduced or possibly eliminated the $\mathrm{Cl}^{-}$retention in the $\mathrm{FAPbI}_{3-x} \mathrm{Cl}_{X}$ crystals [66]. During the treatment of $\mathrm{FAPbI}_{3-x} \mathrm{Cl}_{x}$, water vapor induced halide loss in the perovskite crystals. The chemical bonds between chlorine and its surrounding elements are extremely weak and can be easily broken by residual water vapor. Yang et al. further combined hot-casting technology with methylamine (MA) gas treatment to prepare dense and uniform perovskite films under high relative humidity [67]. Porous and rough $\mathrm{MAPbI}_{3}$ perovskite films prepared using hot casting can be transformed into dense and high-quality films with MA gas treatment [68]. In addition, Hao et al. treated $\mathrm{MAPbI}_{3}$ perovskite films with nondestructive ethanol/chlorobenzene, resulting in a coarsening of the perovskite grains and lateral grain growth of the $\mathrm{MAPbI}_{3}$ perovskite films [69]. Cheng et al. introduced a thermal radiation hot-casting method to solve the problems of temperature gradient and moisture intrusion during the deposition process [70]. A $500 \mathrm{~W}$ tungsten filament was used as the heat source. A smooth and dense perovskite film was then deposited by controlling the humidity and temperature gradients under ambient air. 


\subsection{Single-Crystal Growth and Other Functional Layers}

A single perovskite crystal exhibits advantages such as high light absorption, a long carrier lifetime, high carrier mobility, low trap state density, and excellent defect tolerance [71]. Liu et al. reported an induced peripheral crystallization (IPC) method to grow single crystals of multiple sizes $\left(\mathrm{C}_{6} \mathrm{H}_{5} \mathrm{C}_{2} \mathrm{H}_{4} \mathrm{NH}_{3}\right)_{2} \mathrm{PbI}_{4}\left(\mathrm{PEA}_{2} \mathrm{PbI}_{4}\right)$. Figure 4a illustrates a schematic of the single-crystal growth process of $\mathrm{PEA}_{2} \mathrm{PbI}_{4}$. The hot precursor solution was transferred to a glass substrate at a constant of $80^{\circ} \mathrm{C}$. Slides are placed on droplets of the precursor solution, followed by squeezing, baking, and cooling. Figure $4 \mathrm{~b}$ shows the growth of $\mathrm{PEA}_{2} \mathrm{PbI}_{4}$ crystals at different stages. At $80{ }^{\circ} \mathrm{C}$, the solution is unsaturated, and thus it is impossible to form microcrystals. The solvent evaporated and the local concentration gradually increased. When the temperature decreased to $72{ }^{\circ} \mathrm{C}$, small crystals formed on the edges of the glass slide. Figure $4 \mathrm{c}$ shows well-shaped single crystals with habitant rectangular a parallelepiped formation in a closed petri dish [71]. In addition, Liu et al. developed a low-temperature
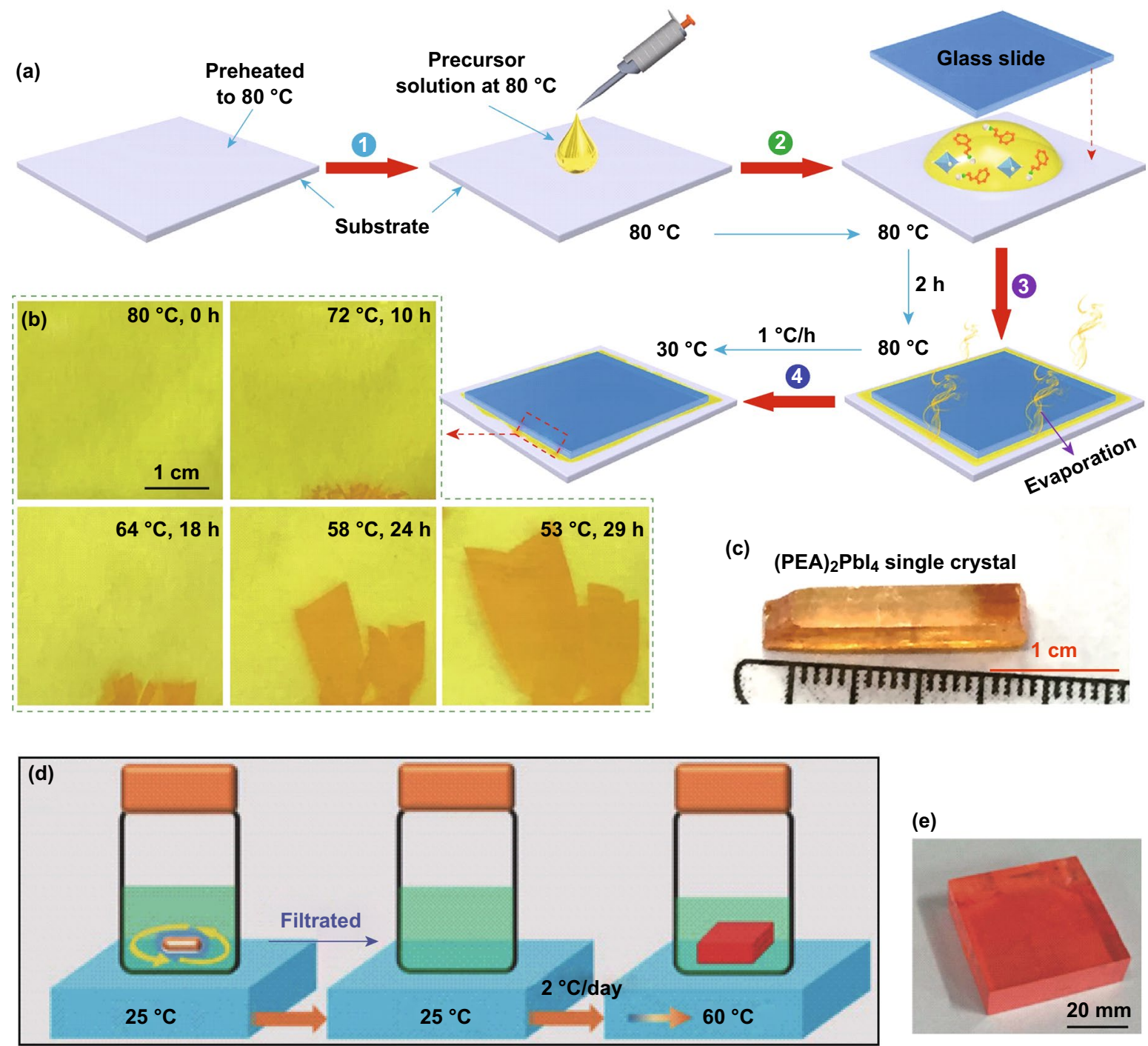

(e)

Fig. 4 a Schematic illustration of the IPC procedure. b Photographs of $\mathrm{PEA}_{2} \mathrm{PbI}_{4}$ taken at different stages of the growth process. $\mathbf{c}$ Photograph of a typical $\mathrm{PEA}_{2} \mathrm{PbI}_{4}$ crystal [71]. Copyright (C) 2018 Elsevier, Ltd. d Schematic illustration of the low-temperature-gradient crystallization (LTGC) process for $\mathrm{MAPbBr}_{3}$ single crystals. e Photograph taken from a MAPbBr 3 single crystal [72]. Copyright @ $2018 \mathrm{WILEY-VCH} \mathrm{Verlag}$ $\mathrm{GmbH} \& \mathrm{Co}$. KGaA, Weinheim 
gradient crystallization method to grow a single crystal of $\mathrm{CH}_{3} \mathrm{NH}_{3} \mathrm{PbBr}_{3}$ with high carrier mobility by adjusting the crystal nucleation and growth, as shown in Fig. 4d, e [72].

A hot-casting technique can also be used to deposit other functional layers (such as $\mathrm{SnO}_{2}, \mathrm{TiO}_{2}, \mathrm{NiO}_{x}$, cuprous thiocyanate $(\mathrm{CuSCN})$, or cuprous iodide (CuI)). For example, Lian et al. reported the hot-substrate deposition of poly(4butylphenyl-diphenyl-amine) (PTPD) as an effective hole transport layer (HTL) and phenyl-C61-butyric acid methyl ester (PCBM) as an electron transport layer (ETL) [73]. The solvent volatilization caused by the hot substrate accelerates the self-organization of the PTPD, thereby improving the adhesion to the substrate with higher coverage and flatness. Hot-cast PCBM films show a higher uniformity and lower roughness, which helps reduce the current leakage and charge recombination. Hao et al. adjusted the deposition temperature of hot-cast $\mathrm{NiO}_{x}$ films to change the coordination structure and charge state of the $\mathrm{NiO}_{x}$. In addition, the hole injection efficiency at the $\mathrm{NiO}_{x}$ /perovskite interface was improved, and the charge accumulation at the interface was effectively avoided [74].

\section{Advantages of Hot-Casting Technique}

\subsection{Grain Size, Film Thickness, and Orientation}

A hot-casting technique has been widely applied to obtain relatively thick and preferentially orientated large-grain perovskite films. The larger grain size endows a reduction of the grain boundaries of the perovskite film. At the same time, there is a positive influence on the absorption, charge transport, and crystallinity of the perovskite films [75-77]. However, the increase in grain size may increase the density of the undesirable pinholes, resulting in direct contact between the HTL and ETL and the leakage current. The voids in the perovskite film will seriously damage the device performance [78-80]. In addition, the optoelectronic performance of the perovskite film is not directly related to the size of the crystalline domains [81]. A thick perovskite layer contributes to the harvesting of sufficient light absorption across the visible light range. In general, the concentration of the precursor solution and the rotation speed can be adjusted to tune the thickness of the perovskite layer. A thickness-insensitive device performance was observed when applying the hot-casting technique, which is important for the large-scale implementation of this deposition technology. When a long-chain organic cation layer is inserted into the inorganic framework to deviate the tolerance factor from a value of 1 , the inorganic halide octahedrons are connected in a common apex and extend in a $2 \mathrm{D}$ direction to form $2 \mathrm{D}$ perovskites [82-85]. The insertion of an organic chain will hinder the charge extraction and collection. It is important to control the growth orientation of a $2 \mathrm{D}$ perovskite film to facilitate carrier transport. A preferentially orientated growth of $2 \mathrm{D}$ perovskites can be obtained through a hot-casting process. This enables the device to achieve an excellent carrier transferability and high PCE. Zhang et al. studied the crystal orientation of RT-cast and hot-cast $\mathrm{BA}_{2} \mathrm{MA}_{3} \mathrm{~Pb}_{4} \mathrm{I}_{13}$ perovskite films using GIWAXS (Fig. 5a, b) [86]. The Debye-Scherrer diffraction rings of a $\mathrm{BA}_{2} \mathrm{MA}_{3} \mathrm{~Pb}_{4} \mathrm{I}_{13}$ film at $\mathrm{RT}$ indicated a random orientation. Otherwise, the $2 \mathrm{D}$ perovskite film deposited using the hot-casting method exhibited sharp and discrete Bragg spots along the same ring, indicative of the preferred orientation of a $\mathrm{BA}_{2} \mathrm{MA}_{3} \mathrm{~Pb}_{4} \mathrm{I}_{13}$ film. A hot-casted film with a strong vertical orientation provides a direct pathway for electron and hole extraction. In addition, it was further reported that the out-of-plane orientation was significantly enhanced in the hot-casted (iso- $\mathrm{BA})_{2}(\mathrm{MA})_{3} \mathrm{~Pb}_{4} \mathrm{I}_{13}$ perovskite film by the sharp spots along $q_{\mathrm{z}}$ in GIWAXS [18]. Kanatzidis et al. reported that a mixed solvent (DMF:DMSO) can induce a better crystallinity and preferential orientation of the hot-casted $\mathrm{BA}_{2} \mathrm{MA}_{4} \mathrm{~Pb}_{5} \mathrm{I}_{16}$ film (Fig. 5c, d) [17]. Compared with a pure DMF solvent, the DMF/DMSO mixed solvent dramatically increased the peak intensity of (111) and (202) by tenfold. As a possible reason for this, a small amount of polarized DMSO (owing to the $\mathrm{S}^{\delta+}=\mathrm{O}^{\delta-}$ polarized bond) in the precursor solution can form strong hydrogen bonds with the organic cation, which helps change the crystallization rate and increase the film crystallinity. This improves the carrier transport by controlling the degree of preferential orientation of the perovskite film. According to the density functional theory (DFT), the interface between the dimensional-reduced perovskite nuclei and the $\mathrm{TiO}_{2}$ substrate was calculated and analyzed (Fig. 5e) [87]. BA- and MA-attached $\mathrm{TiO}_{2}$ substrates represent parallel and perpendicular orientations, respectively. After the geometry optimization, the interfacial energy of parallel and perpendicular orientated (BA) $)_{2}(\mathrm{MA})_{3} \mathrm{~Pb}_{4} \mathrm{I}_{13} / \mathrm{TiO}_{2}$ is 0.5 and $8.9 \mathrm{eV}$, respectively. It is inferred that when a $(\mathrm{BA})_{2}(\mathrm{MA})_{3} \mathrm{~Pb}_{4} \mathrm{I}_{13}$ nucleus is formed on a $\mathrm{TiO}_{2}$ substrate, perpendicular orientations are highly thermodynamically preferred. 
(a)

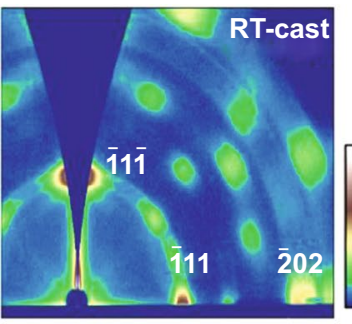

(b)

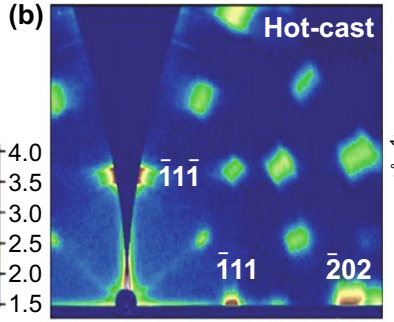

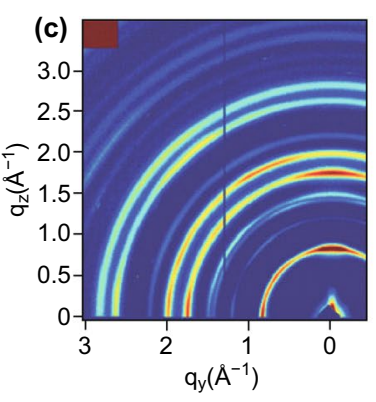

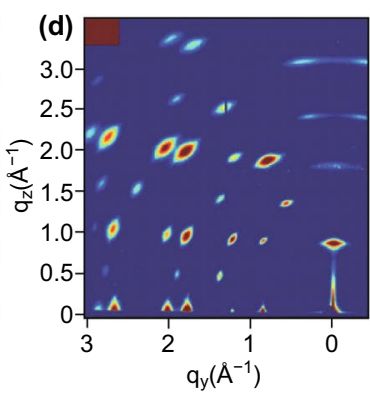

(e)
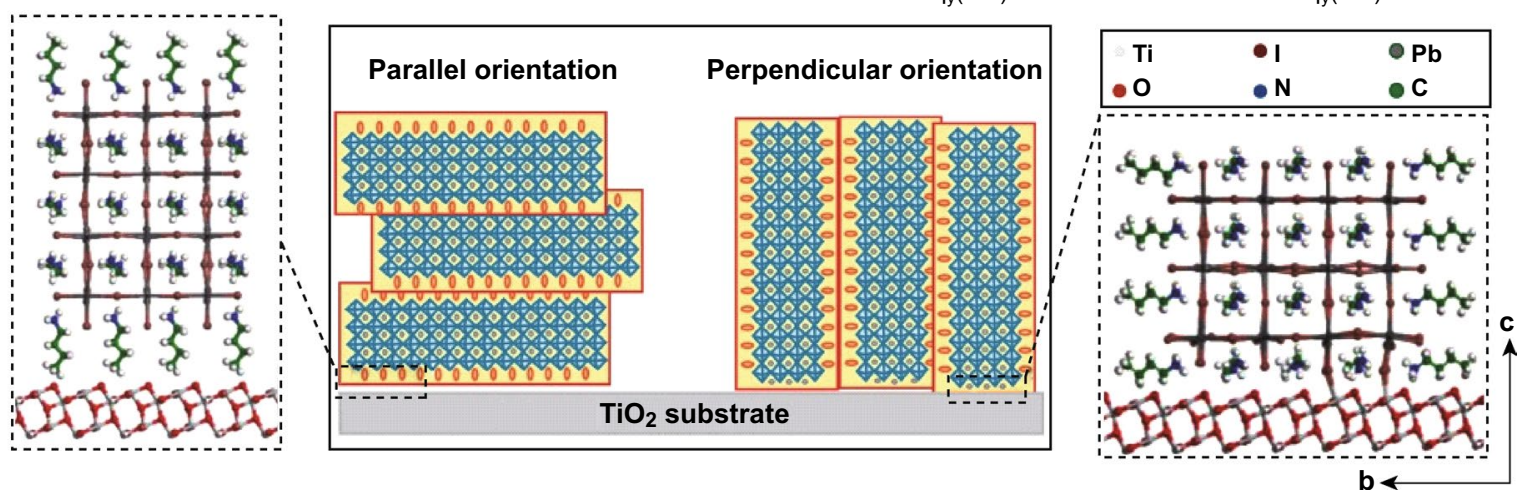

Fig. 5 2D GIWAXS plots of $\mathrm{BA}_{2} \mathrm{MA}_{3} \mathrm{~Pb}_{4} \mathrm{I}_{13}$ films processed using a RT casting and b hot casting [86]. Copyright (C) 2019 Elsevier Ltd. $\mathbf{c}$ GIWAXS data of the hot-cast films from DMF and $\mathbf{d}$ from the optimized 3:1 DMF: DMSO mixed solvent [17]. Copyright (C) 2017 WILEY-VCH Verlag $\mathrm{GmbH} \& \mathrm{Co} . \mathrm{KGaA}$, Weinheim. e Titanium oxide/(BA) ${ }_{2}(\mathrm{MA})_{3} \mathrm{~Pb}_{4} \mathrm{I}_{13}$ interface (optimized structures) for the parallel orientation (left) and perpendicular orientation (right) conditions [87]. Copyright @ 2018 WILEY-VCH Verlag GmbH \& Co. KGaA, Weinheim

\subsection{Defects and Recombination}

A nonradiative recombination deteriorates the PSC performance through the following pathways. The electrons fall back to the valence band, resulting in radiative recombination. Holes (electrons) are transferred back to the perovskite layer, resulting in minority recombination at the interface. The perovskite layer with pores will then cause direct contact with the functional layers, thereby generating carrier recombination. Numerous defect states in the device form recombination centers to capture the carriers, causing a nonradiative recombination process. Some deep-level traps are the main pathway for a carrier loss. In addition, the nonradiative recombination of carriers inside the device also directly affects the achievable $V_{\text {oc }}$ of the PSCs. Therefore, the deposition of low-defective perovskite thin films is important for suppressing nonradiative recombination. For hot-casted perovskite films, large grain sizes help reduce the number of grain boundaries to suppress the charge trapping. PL and TRPL have been widely used to study the charge carrier kinetics of perovskite films deposited using conventional RT-casting and a hot-casting technique. As shown in Fig. 6a, b, the PL intensity and carrier lifetime of the hot-cast perovskite film are much higher than that of the RT-cast film, indicating a significant decrease in the nonradiative recombination rate in the hot-cast $\mathrm{CsPbI}_{2} \mathrm{Br}$ film. Figure $6 \mathrm{c}$ depicts the calculated density of state (DOS) from the impedance spectroscopy for 1- and 48-h aged devices, respectively. Both DOS values fluctuate at approximately $1.7 \times 10^{17} \mathrm{~cm}^{-3}$. The 48 -h aging device tends to make trap state peaks toward lower frequencies, indicative of shallow trap energy and low-frequency dielectric loss related to the reduced grain boundaries in the perovskite film. Figure $6 \mathrm{~d}$ shows the dependence of the measured $V_{\mathrm{oc}}$ as a function of incident light intensity for a large-grain device $\left(180^{\circ} \mathrm{C}\right)$ and a small-grain device $\left(100{ }^{\circ} \mathrm{C}\right)$. The linear-fitting slope of the small-grain device was $1.64 k_{\mathrm{B}} T / q$, which was significantly higher than that of a large-grain device $\left(1.02 k_{\mathrm{B}} T / q\right)$. This difference indicates a more severe trap-assisted recombination in the device with smaller grain size. Meanwhile, hotcasted devices have higher rectification coefficients and less leakage current in the dark current curves (Fig. 6e), which 

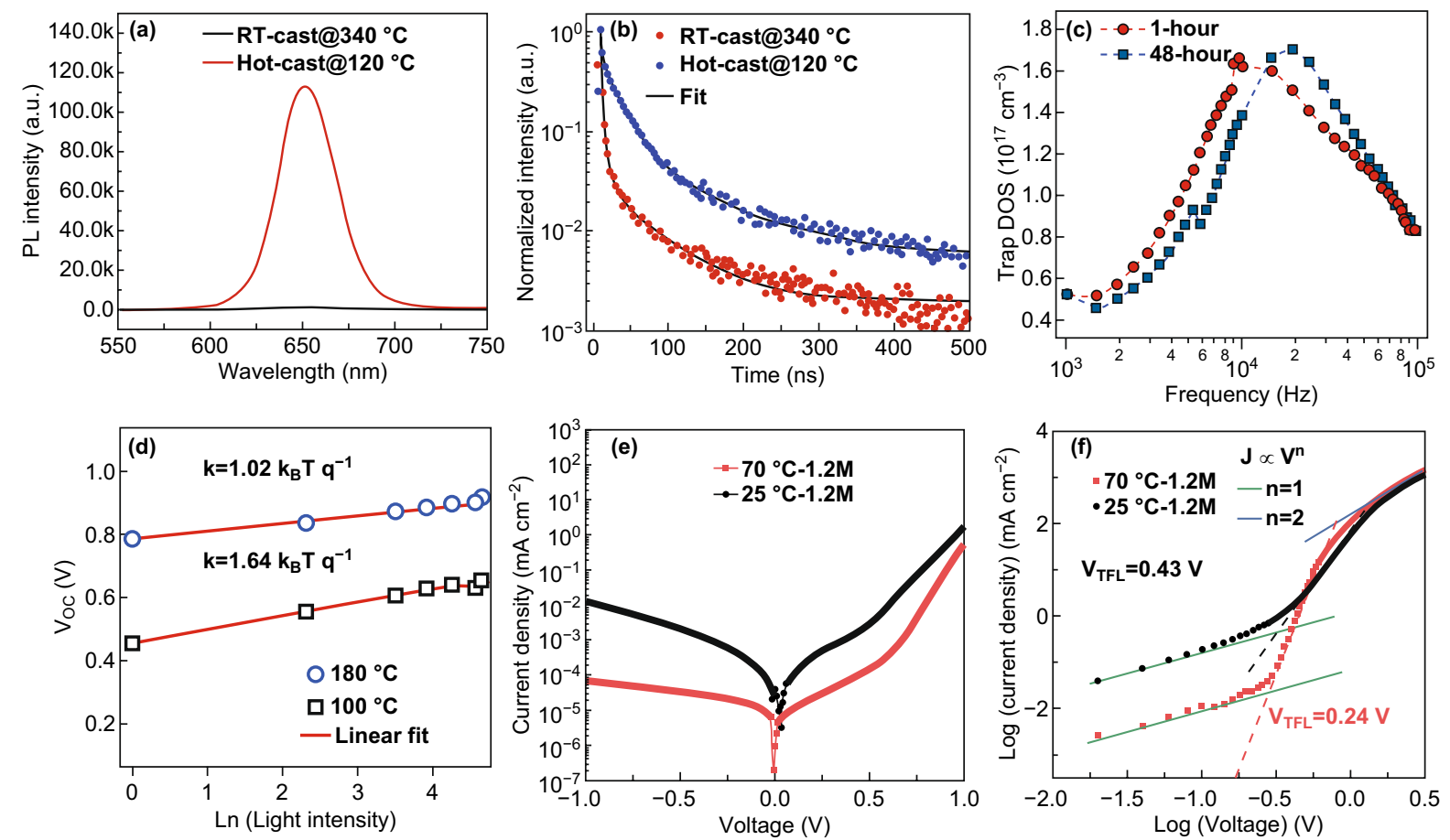

Fig. 6 a, b PL and TRPL spectra of $\mathrm{CsPbI}_{2} \mathrm{Br}$ films fabricated using RT and hot casting [88]. Copyright (c) 2019 The Royal Society of Chemistry. c Trap density of states for the device with 1-h and 48-h aged perovskite precursors [46]. Copyright (C) 2017 WILEY-VCH Verlag GmbH \& Co. KGaA, Weinheim. $\mathbf{d} V_{\mathrm{oc}}$ as a function of illumination light intensity for a large-grain device $\left(180{ }^{\circ} \mathrm{C}\right)$ and a small-grain device (100 $\left.{ }^{\circ} \mathrm{C}\right)$ [19]. Copyright (ㅇ 2017 American Association for the Advancement of Science. e $J-V$ characteristics of PSCs swept from 1.0 to $-1.0 \mathrm{~V}$ in the dark. f $J-V$ characteristics of hole-only devices [53]. Copyright ( 2016 WILEY-VCH Verlag GmbH \& Co. KGaA, Weinheim

means smaller recombination compared to the RT-casted device. Figure $6 \mathrm{f}$ shows the $J-V$ characteristics of hole-only devices with an $\mathrm{ITO} / \mathrm{NiO}_{x} /$ perovskite/PTAA/ $/ \mathrm{MoO}_{3} / \mathrm{Ag}$ configuration to estimate the hole mobility and defect density of perovskite films deposited at different temperatures. The defect densities of devices fabricated at 70 and $25^{\circ} \mathrm{C}$ were derived as $1.00 \times 10^{15} \mathrm{~cm}^{-3}$ and $7.50 \times 10^{15} \mathrm{~cm}^{-3}$, respectively. This was mainly due to the increase in grain size and the boundary reduction of devices deposited at $70^{\circ} \mathrm{C}$.

\subsection{Efficiency and Stability}

\subsubsection{Device Performance}

The PCE, stability, and cost are three main limiting factors for the practical application of PSCs. Table 1 summarizes the recent advances of PCEs when using a hot-casting technique. $\mathrm{MAPbI}_{3}$ and $\mathrm{FAPbI}_{3}$ are the two dominant light harvesters in PSCs, with energy bandgaps of 1.55 and $1.47 \mathrm{eV}$ and a theoretical maximum PCE of $31.3 \%$ and $32.5 \%$, respectively [ 89 , 90]. Nie et al. first reported the fabrication of a millimeter grain size of perovskite films, enabling a PCE of $17.48 \%$ with negligible hysteresis [19]. Marks et al. reported a hotcasting process to control the $\mathrm{Cl}^{-}$incorporation and achieved a PCE of $18.2 \%$ for a small area $\left(0.09 \mathrm{~cm}^{2}\right)$ and $15.4 \%$ for a large area $\left(1 \mathrm{~cm}^{2}\right)$ [11]. Chen et al. reported the deposition of an 850-nm-thick perovskite film together with a PCE of up to $19.54 \%$ [53]. Tsai et al. reported a $12.52 \%$ PCE without hysteresis based on $\mathrm{BA}_{2} \mathrm{MA}_{3} \mathrm{~Pb}_{4} \mathrm{I}_{13} 2 \mathrm{D}$ perovskite [91]. We believe that the PCE of PSCs using a hot-casting technology can catch up to that using a solution method in the future. Meanwhile, the improvement in the long-term stability for PSCs is closely related to the perovskite composition [17, 24, 92], device structure [93], and encapsulation [11].

\subsubsection{Stability}

During the film deposition, device testing and storage, both water and oxygen directly affect the PSC performance and stability [102-104]. Taking $\mathrm{MAPbI}_{3}$ as an example, first, water vapor can dissolve the perovskite material (3), and 
Table 1 Summary of photovoltaic parameters for PSCs with hot-casting technique

\begin{tabular}{|c|c|c|c|c|c|c|}
\hline Perovskites & Device structure & $V_{\mathrm{oc}}(\mathrm{V})$ & $J_{\mathrm{sc}}\left(\mathrm{mA} \mathrm{cm}^{-2}\right)$ & FF & $\operatorname{PCE}(\%)$ & Refs. \\
\hline $\mathrm{MAPbI}_{3-x} \mathrm{Cl}_{x}$ & FTO/PEDOT:PSS/perovskite/PCBM/Al & 0.94 & 22.40 & 0.83 & 17.48 & [19] \\
\hline $\mathrm{MAPbI}_{3}$ & $\mathrm{FTO} / \mathrm{NiO}_{x} /$ perovskite/PCBM/Ag & 1.11 & 21.14 & 0.80 & 18.84 & [94] \\
\hline $\mathrm{MAPbI}_{3-x} \mathrm{Cl}_{x}$ & $\mathrm{FTO} / \mathrm{SnO}_{2} /$ perovskite/spiro-OMeTAD/Au & 1.12 & 22.50 & 0.76 & 19.10 & {$[70]$} \\
\hline $\mathrm{MAPbI}_{3-x} \mathrm{Cl}_{x}$ & $\mathrm{FTO} / \mathrm{c}-\mathrm{TiO}_{2} /$ perovskite/PTAA/Au & 1.10 & 21.40 & 0.78 & 18.30 & [95] \\
\hline $\mathrm{MA}_{0.6} \mathrm{FA}_{0.38} \mathrm{Cs}_{0.02} \mathrm{PbI}_{2.975} \mathrm{Br}_{0.025}$ & ITO/PTAA/perovskite/C $60 / \mathrm{BCP} / \mathrm{Cu}$ & 1.09 & 23.10 & 0.77 & 19.50 & [96] \\
\hline $\mathrm{MAPbI}_{3}$ & $\mathrm{FTO} / \mathrm{c}-\mathrm{TiO}_{2} /$ perovskite/spiro-OMeTAD/Ag & 1.00 & 20.60 & 0.64 & 13.1 & {$[37]$} \\
\hline $\mathrm{MAPbI}_{3-x} \mathrm{CI}_{x}$ & ITO/PEDOT:PSS/perovskite/PCBM/LiF/Al & 1.00 & 18.60 & 0.75 & 14.6 & {$[22]$} \\
\hline $\mathrm{MAPbI}_{3-x} \mathrm{CI}_{x}$ & $\mathrm{FTO} / \mathrm{NiO}_{X} /$ perovskite/PCBM/PEI/Ag & 1.08 & 21.2 & 0.79 & 18.2 & {$[11]$} \\
\hline $\mathrm{MAPbI}_{3-x-y} \mathrm{Br}_{x} \mathrm{CI}_{y}$ & ITO/PEDOT:PSS/perovskite/ $\mathrm{PC}_{61} \mathrm{BM} / \mathrm{Ca} / \mathrm{Al}$ & 1.10 & 19.25 & 0.78 & 16.52 & {$[51]$} \\
\hline $\mathrm{FA}_{0.25} \mathrm{MA}_{0.75} \mathrm{PbI}_{3}$ & $\mathrm{FTO} / \mathrm{c}-\mathrm{TiO}_{2} /$ perovskite/spiro-OMeTAD/Au & 0.97 & 22.8 & 0.66 & 14.6 & {$[54]$} \\
\hline $\mathrm{MAPbI}_{3-x} \mathrm{CI}_{x}$ & ITO/PEDOT:PSS/perovskite/PCBM/Al & 0.94 & 20.92 & 0.77 & 15.22 & [46] \\
\hline $\mathrm{MAPbI}_{3}$ & $\mathrm{ITO} / \mathrm{NiO}_{X} / \mathrm{MAPbI}_{3} / \mathrm{PCBM} / \mathrm{BCP} / \mathrm{Ag}$ & 1.11 & 22.70 & 0.78 & 19.54 & {$[53]$} \\
\hline $\mathrm{MAPbI}_{3}$ & $\mathrm{FTO} / \mathrm{c}-\mathrm{TiO}_{2} / \mathrm{m}^{-\mathrm{TiO}_{2}} /$ perovskite/spiro-OMeTAD$/ \mathrm{Au}$ & 1.07 & 21.32 & 0.70 & 16.01 & {$[56]$} \\
\hline $\mathrm{MAPbI}_{3}$ & ITO/PEDOT:PSS/perovskite/PCBM/Ag & 0.92 & 21.96 & 0.70 & 14.24 & {$[67]$} \\
\hline $\mathrm{FAPbI}_{3-x} \mathrm{CI}_{x}$ & $\mathrm{FTO} / \mathrm{c}-\mathrm{TiO}_{2} /$ perovskite/spiro-OMeTAD/Ag & 0.96 & 18.93 & 0.66 & 12.07 & {$[66]$} \\
\hline $\mathrm{MAPbI}_{3}$ & $\mathrm{FTO} / \mathrm{c}-\mathrm{TiO}_{2} /$ perovskite/spiro-OMeTAD/Au & 1.01 & 21.80 & 0.74 & 16.32 & [64] \\
\hline $\mathrm{MAPbI}_{3}$ & $\mathrm{FTO} / \mathrm{c}-\mathrm{TiO}_{2} /$ perovskite/spiro-OMeTAD/Au & 1.07 & 22.67 & 0.77 & 18.74 & [97] \\
\hline $\mathrm{CsPbI}_{2} \mathrm{Br}$ & $\mathrm{ITO} / \mathrm{SnO}_{2} /$ perovskite/PTAA$/ \mathrm{MoO}_{3} / \mathrm{Al}$ & 1.19 & 14.54 & 0.74 & 13.80 & {$[88]$} \\
\hline $\mathrm{Ag}_{2} \mathrm{BiI}_{5}$ & $\mathrm{FTO} / \mathrm{c}-\mathrm{TiO}_{2} / \mathrm{m}-\mathrm{TiO}_{2} /$ perovskite/PTAA$/ \mathrm{Au}$ & 0.69 & 6.04 & 0.62 & 2.60 & {$[92]$} \\
\hline $\mathrm{BA}_{2} \mathrm{MA}_{4} \mathrm{~Pb}_{5} \mathrm{I}_{16}$ & ITO/PEDOT:PSS/perovskite/PCBM/Al & 1.00 & 11.44 & 0.75 & 8.71 & {$[23]$} \\
\hline $\mathrm{BA}_{2} \mathrm{MA}_{3} \mathrm{~Pb}_{4} \mathrm{I}_{13}$ & $\mathrm{FTO} / \mathrm{c}-\mathrm{TiO}_{2} / \mathrm{m}^{-\mathrm{TiO}_{2}} /$ perovskite/spiro-OMeTAD/Au & 0.97 & 17.19 & 0.53 & 9.03 & [98] \\
\hline $\mathrm{BA}_{2} \mathrm{MA}_{3} \mathrm{~Pb}_{4} \mathrm{I}_{13}$ & FTO/PEDOT:PSS/perovskite/PCBM/Al & 1.01 & 16.76 & 0.74 & 12.52 & {$[91]$} \\
\hline $\mathrm{BA}_{2} \mathrm{MA}_{3} \mathrm{~Pb}_{4} \mathrm{I}_{13}$ & ITO/PTAA/layer perovskite/PCBM/BCP/Cu & 1.13 & 18.90 & 0.59 & 12.7 & {$[24]$} \\
\hline$(\mathrm{CPEA})_{2} \mathrm{MA}_{4} \mathrm{~Pb}_{5} \mathrm{I}_{16}$ & $\mathrm{FTO} / \mathrm{c}-\mathrm{TiO}_{2} /$ perovskite/spiro-OMeTAD/Au & 0.99 & 19.92 & 0.60 & 11.86 & [99] \\
\hline $\mathrm{BA}_{2} \mathrm{MA}_{3} \mathrm{~Pb}_{4} \mathrm{I}_{13}$ & $\mathrm{FTO} / \mathrm{c}-\mathrm{TiO}_{2} /$ perovskite/spiro-OMeTAD/Au & 1.08 & 19.45 & 0.58 & 12.17 & {$[87]$} \\
\hline $\mathrm{MA}_{2} \mathrm{PbI}_{4}$ & $\mathrm{FTO} / \mathrm{c}-\mathrm{TiO}_{2} /$ perovskite/spiro-OMeTAD/Au & 1.06 & 21.00 & 0.76 & 16.92 & {$[100]$} \\
\hline$(\mathrm{GA})(\mathrm{MA})_{3} \mathrm{~Pb}_{3} \mathrm{I}_{10}$ & $\mathrm{FTO} / \mathrm{c}-\mathrm{TiO}_{2} /$ perovskite/spiro-OMeTAD/Au & 1.00 & 20.70 & 0.66 & 13.87 & [101] \\
\hline
\end{tabular}

\# FTO, fluorine-doped tin oxide; ITO, indium-tin-oxide; $\mathrm{SnO}_{2}$, tin oxide; $\mathrm{TiO}_{2}$, titanium dioxide; PCBM, phenyl C61 butyric acid methyl ester; Al, aluminum; Ag, silver; Au, gold; PTAA, poly[bis(4-phenyl)(2,4,6-trimethylphenyl)aMine]; LiF, lithium fluoride; spiro-OMeTAD, 2,2',7,7'-tetrakis( $N, N$-di- $p$-methoxyphenylamine)-9,9'-spirobifluorene; $\mathrm{CPEA}, \mathrm{ClC}_{6} \mathrm{H}_{4} \mathrm{C}_{2} \mathrm{H}_{4} \mathrm{NH}_{3}{ }^{+}$; GA, guanidinium

MAI is then decomposed to form a mixture of MA and HI (4); however, $\mathrm{HI}$ will either react with $\mathrm{O}_{2}$ to form $\mathrm{H}_{2} \mathrm{O}$ and $\mathrm{I}_{2}(5)$, or self-decompose (6). In general, $\mathrm{MAPbI}_{3}$ continues to decompose after exposure to moisture.

$$
\begin{aligned}
& \mathrm{CH}_{3} \mathrm{NH}_{3} \mathrm{PbI}_{3}(\mathrm{~s}) \stackrel{\mathrm{H}_{2} \mathrm{O}}{\leftrightarrow} \mathrm{CH}_{3} \mathrm{NH}_{3} \mathrm{I}(\mathrm{aq})+\mathrm{PbI}_{2}(\mathrm{~s}) \\
& \mathrm{CH}_{3} \mathrm{NH}_{3} \mathrm{I}(\mathrm{aq}) \leftrightarrow \mathrm{CH}_{3} \mathrm{NH}_{2}(\mathrm{aq})+\mathrm{HI}(\mathrm{aq}) \\
& 4 \mathrm{HI}(\mathrm{aq})+\mathrm{O}_{2}(\mathrm{~g}) \leftrightarrow 2 \mathrm{I}_{2}(\mathrm{~s})+2 \mathrm{H}_{2} \mathrm{Oi} \\
& 2 \mathrm{HI}(\mathrm{aq}) \stackrel{h v}{\leftrightarrow} \mathrm{H}_{2} \mathrm{~g}+\mathrm{I}_{2}(\mathrm{~s}) .
\end{aligned}
$$

The poor stability of a PSC device severely limits its commercialization. Adjusting the $\mathrm{ABX}_{3}$ perovskite composition and/or increasing the crystalline quality is key in improving long-term stability. In this regard, long-chain organic cations $\left({ }^{+} \mathrm{NH}_{3}-\mathrm{R}-\mathrm{NH}_{3}{ }^{+}\right.$or $\left.\mathrm{R}-\mathrm{NH}_{3}{ }^{+}\right)$have been widely introduced as a substitute to a site cations. These $2 \mathrm{D}$ perovskites exhibit excellent long-term stability [62, 91], in which the organic layer and the inorganic layer alternately form a layered structure. The larger organic cations in the $2 \mathrm{D}$ perovskite crystal structure improve the humidity stability owing to the hydrophobic nature of long-chain organic cations. Pure 2D PSCs exhibit good stability but low PCE [17, 23]. Interestingly, excellent optoelectronic properties and stability can be achieved by combining 3D perovskite and 2D Ruddlesden-Popper perovskite [105, 106]. To successfully achieve this $3 \mathrm{D} / 2 \mathrm{D}$ structure, it is necessary to control the growth direction allowing the carriers to be transported across the 
(a)

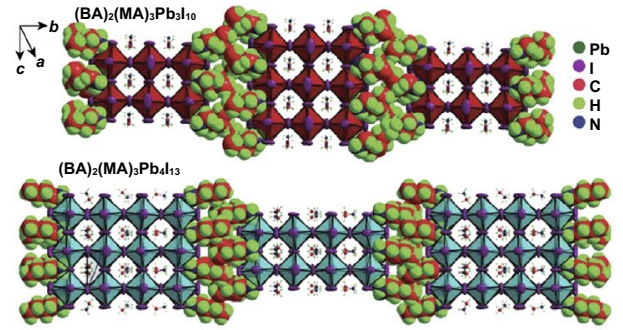

(b)

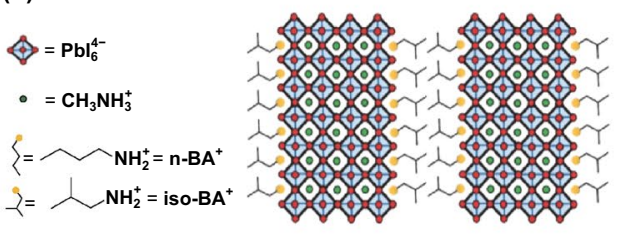

(c)
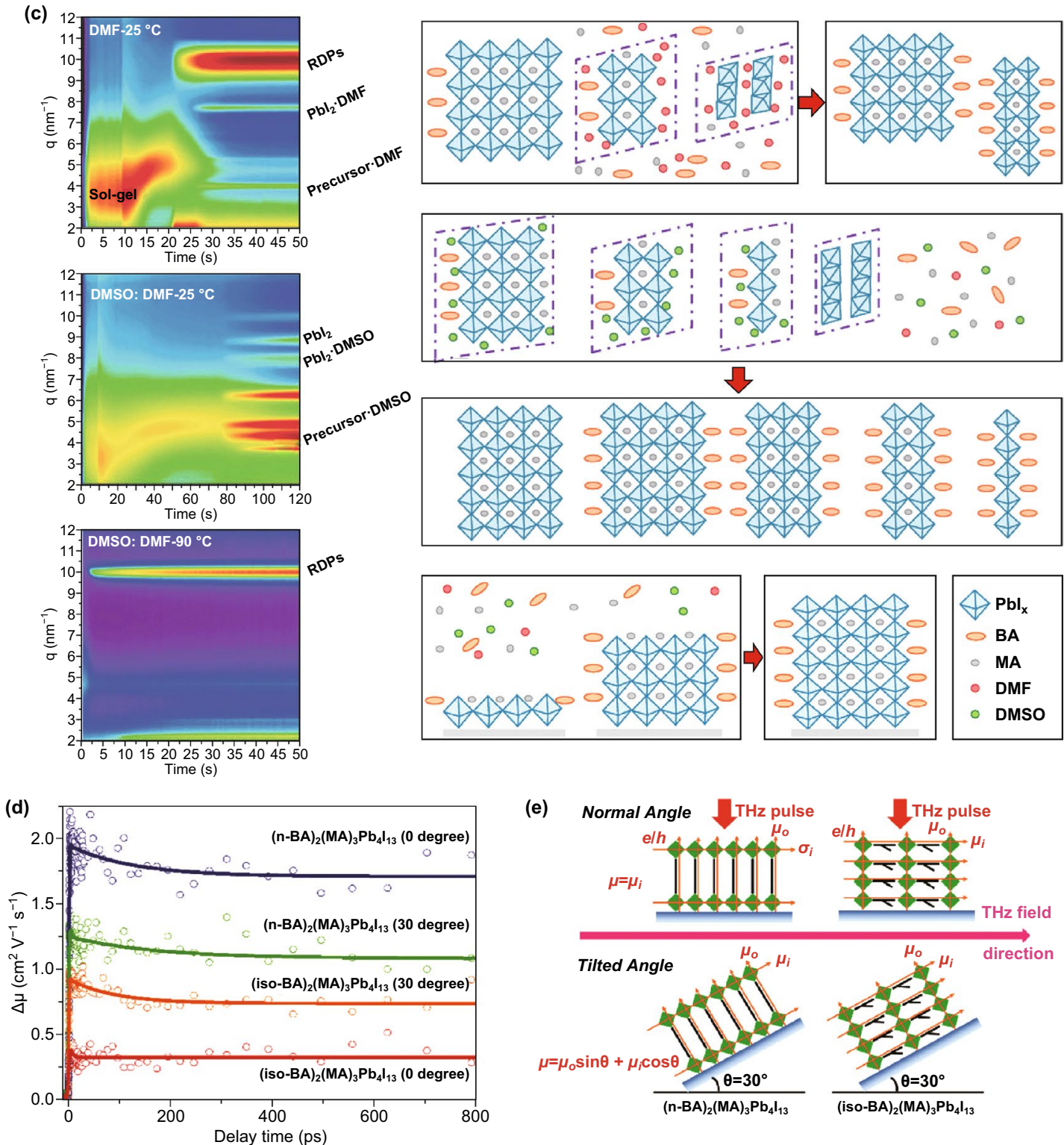

Fig. 7 Schematic illustration of perovskite crystal structures: a $(\mathrm{BA})_{2}(\mathrm{MA})_{3} \mathrm{~Pb}_{4} \mathrm{I}_{13}$ and $(\mathrm{BA})_{2}(\mathrm{MA})_{3} \mathrm{~Pb}_{4} \mathrm{I}_{13}$; b (iso- $\left.\mathrm{BA}\right)_{2}(\mathrm{MA})_{3} \mathrm{~Pb} \mathrm{I}_{13}$. Copyright (C) 2017 WILEY-VCH Verlag GmbH \& Co. KGaA, Weinheim. c In situ GIWAXS measurements and schematic models [87]. Copyright (C) 2018 WILEY-VCH Verlag GmbH \& Co. KGaA, Weinheim. d The photoconductivity kinetics from TRTS for RT $(n-B A)_{2}\left(\mathrm{MA}_{3} \mathrm{~Pb} \mathrm{I}_{43}\right.$ and (iso-BA) $)_{2}(\mathrm{MA})_{3} \mathrm{~Pb}_{4} \mathrm{I}_{13}$ films excited at $400 \mathrm{~nm}$ under an excitation density of $3.4 \times 10^{13} \mathrm{ph} \mathrm{cm}^{-2}$ pulse $\mathrm{c}^{-1}$ with a different pump-probe geometry at both normal positions. e Schematics of the composition of the charge mobility detected by TRTS with different incident angles of THz probe pulse for two samples. Copyright @ 2017 WILEY-VCH Verlag GmbH \& Co. KGaA, Weinheim 
plane; otherwise, the transmission of photogenerated charge carriers will be inhibited by the long organic chain. Perovskite films grown perpendicular to the substrate direction can be obtained using hot-casting techniques. This allows the device to achieve an excellent carrier transportability and high PCE (Fig. 7a, b). Kanatzidis et al. conducted stability tests for $\mathrm{BA}_{2} \mathrm{MA}_{4} \mathrm{~Pb}_{5} \mathrm{I}_{16}$ films in ambient air $(\mathrm{RH} \approx 30 \%)$. A $\mathrm{BA}_{2} \mathrm{MA}_{4} \mathrm{~Pb}_{5} \mathrm{I}_{16}$ film exhibits excellent environmental stability [17]. The 2D perovskite deposited using a hot-casting technique can maintain its inherent performance for a long timeframe, indicating superior stability under humid and other environmental conditions [18]. Figure 7c schematically illustrates that a hot substrate can promote a rapid transition from a disordered precursor solution to a perovskite phase without the growth of an intermediate phase, thereby obtaining a low-dimensional perovskite film with a vertical orientation and a high phase purity [87]. The carrier transport dynamics of $2 \mathrm{D}$ perovskites have been recognized to be related to the differences in the crystal orientation. Liang et al. used time-resolved terahertz (THz) spectroscopy (TRTS) to measure the photoconductivity kinetics of n-BA and iso-BA-based 2D perovskites from the transient charge carrier mobility $(\Delta \mu)$, in-plane mobility $\left(\mu_{\mathrm{i}}\right)$, and outof-plane mobility $\left(\mu_{\mathrm{o}}\right)$. A THz probe beam is perpendicular to the (n-BA) $)_{2}(\mathrm{MA})_{3} \mathrm{~Pb}_{4} \mathrm{I}_{13}$ and (iso-BA) ${ }_{2}(\mathrm{MA})_{3} \mathrm{~Pb}_{4} \mathrm{I}_{13}$ films (Fig. $7 \mathrm{~d}$ ). The measured carrier mobilities were 1.88 and $0.38 \mathrm{~cm}^{2} \mathrm{~V}^{-1} \mathrm{~s}^{-1}$ at $2 \mathrm{ps}$, respectively. The value of $\mu_{\mathrm{o}}$ of (iso-BA) ${ }_{2}(\mathrm{MA})_{3} \mathrm{~Pb}_{4} \mathrm{I}_{13}\left(1.35 \mathrm{~cm}^{2} \mathrm{~V}^{-1} \mathrm{~s}^{-1}\right.$ ) was much higher than that of (n-BA) $)_{2}(\mathrm{MA})_{3} \mathrm{~Pb}_{4} \mathrm{I}_{13}$. The (iso-BA) $)_{2}(\mathrm{MA})_{3} \mathrm{~Pb}_{4} \mathrm{I}_{13}$ perovskite film exhibits a strong crystalline orientation, which increases charge mobility [18].

All inorganic perovskites are also a promising choice for improving the long-term stability, which have better thermal stability owing to the presence of an inorganic cation with a higher thermal decomposition temperature. Zheng et al. adopted hot casting to deposit an inorganic $\mathrm{CsPbI}_{2} \mathrm{Br}$ perovskite film at low temperatures [88]. The phase transition temperature of $\mathrm{CsPb}_{2} \mathrm{Br}$ was reduced to $120{ }^{\circ} \mathrm{C}$, and a dense and pinhole-free $\mathrm{CsPbI}_{2} \mathrm{Br}$ perovskite film with a large grain size was formed. An ultrahigh substrate temperature is not necessary for the hot-casting process. Zhao et al. evaluated the thermodynamic stability of the materials through DFT calculations [107]. The positive decomposition enthalpy $\left(\Delta H_{\text {dec }}\right)$ of $\mathrm{CsPbBr}_{3}$ indicates high thermodynamic stability. This is different from that of $\mathrm{CsPbI}_{3}, \mathrm{CsPbI}_{2} \mathrm{Br}$, and $\mathrm{CsPbBr}_{2} \mathrm{I}$ with a negative
$\Delta H_{\mathrm{dec}}$. Song et al. deposited a uniform large-area cesiumbased 2D perovskite thin film using hot-casting technology. Compared with an RT-casting film, a hot-casting film has a higher PL strength and longer carrier life [108]. Mathews et al. deposited silver bismuth iodide $\left(\mathrm{AgBiI}_{4}\right.$ and $\left.\mathrm{Ag}_{2} \mathrm{BiI}_{5}\right)$ through dynamic hot casting under an ambient atmosphere [92]. The hot-casting technique facilitates the deposition of a needle-free uniform film with a large grain size by increasing the solubility of AgI.

\subsection{Upscaling Deposition}

As a solution-processable photovoltaic technology, hot casting is mostly applied to small area devices $\left(<1 \mathrm{~cm}^{2}\right)$ in the laboratory. Based on the rapid development and advantages of hot-casting technology, integration with other scalable deposition technologies is a promising way to achieve upscaled manufacturing of PSCs. The basic idea of hot-casting technology is to stabilize the temperature of the substrate and precursor solution concurrently, thereby affecting the nucleation rate and film morphology through a rapid supersaturation of the precursor solution. Coincidentally, the substrate temperature has been reported to have an important effect on the film morphology in blade coating, spray coating, and inkjet printing. Figure 8 a schematically illustrates the blade coating deposition on a hot substrate [96, 109-111]. Huang et al. introduced a small amount of $\mathrm{Cs}^{+}$cations and $\mathrm{Br}^{-}$anions into the perovskite precursor solution to obtain a $\mathrm{MA}_{0.6} \mathrm{FA}_{0.38} \mathrm{Cs}_{0.02} \mathrm{PbI}_{2.975} \mathrm{Br}_{0.025}$ film and improve the phase purity [96]. The rapid film-forming process of the hot-casting technique may be effective in suppressing the "solution flow" during the dry film stage. Bénard-Marangoni convection caused by the thermal gradient cannot be ignored in a $\mathrm{CsPbI}_{2} \mathrm{Br}$ fluid, which will pull the accumulated solutes in an area with the highest surface tension and inhibit the formation of a continuous film (Fig. 8b) [107]. At the optimal processing temperature of $80^{\circ} \mathrm{C}$, a large-area, high-crystallinity, uniform, and pinhole-free $\mathrm{CsPbI}_{2} \mathrm{Br}$ film can be obtained. The slow solvent removal and the presence of intermediate phases during the thermal annealing result in poor film coverage and low crystalline quality of the RT-casted film. The hot casting at $150{ }^{\circ} \mathrm{C}$ induces a direct crystal growth, which allows the 
(a)

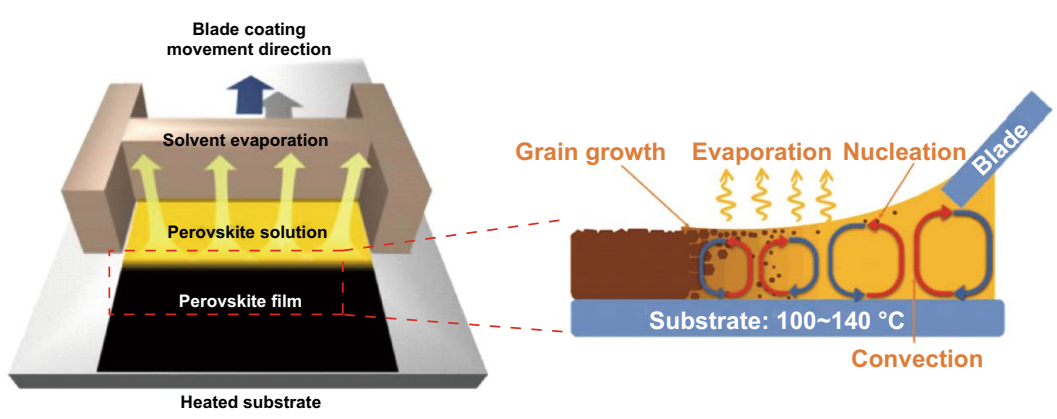

(b)

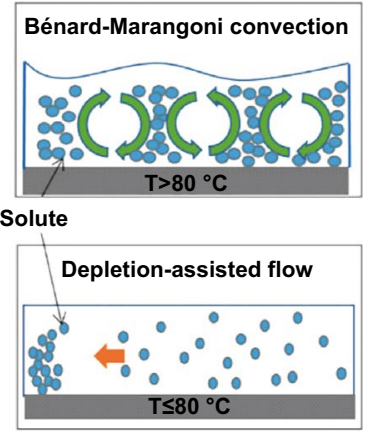

(c)
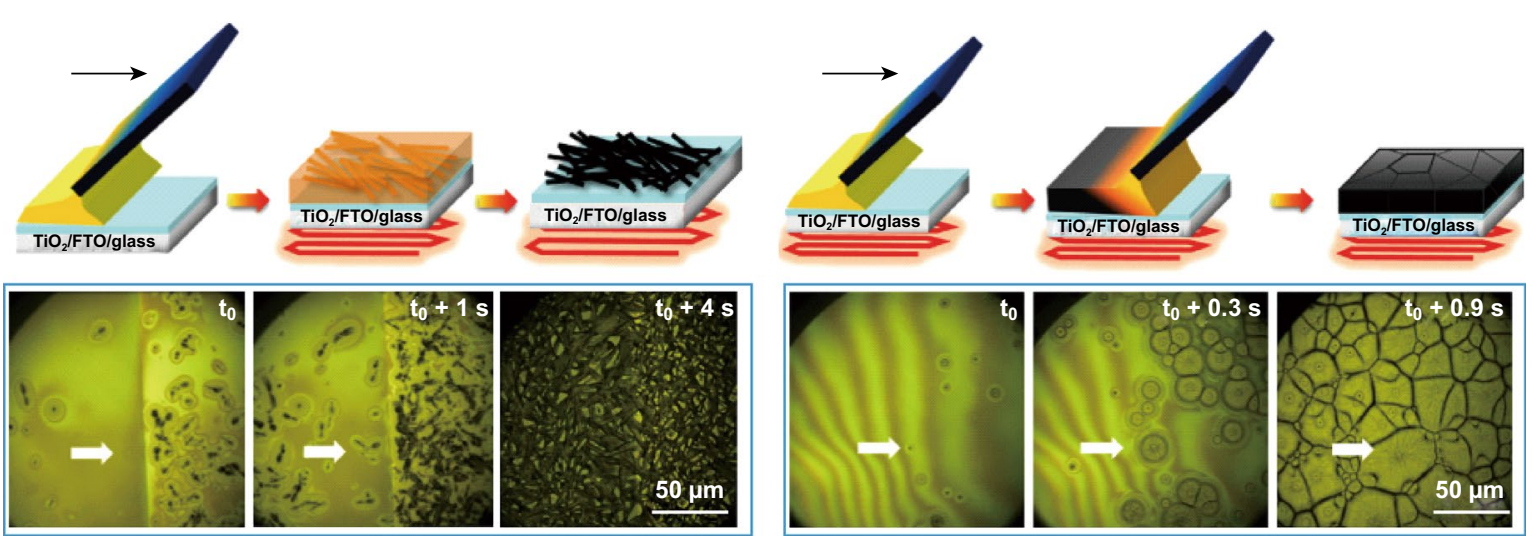

Fig. 8 a Scheme of the doctor-blade coating method [96]. Copyright @ 2017 WILEY-VCH Verlag GmbH \& Co. KGaA, Weinheim. b Schematic illustration of the Bénard-Marangoni convection and depletion-assisted flow of $\mathrm{CsPbI}_{2} \mathrm{Br}$ fluid at higher and lower processing temperatures, respectively [107]. Copyright @ 2019 Elsevier Inc. c Schematic of the process and real-time optical microscopy: DMSO:GBL-blade-25 ${ }^{\circ} \mathrm{C}$ film and DMSO:GBL-blade- $150^{\circ} \mathrm{C}$ film during thermal annealing [97]. Copyright $@ 2018$ Elsevier Inc.

formation of a compact, pinhole-free, and uniform film (Fig. 8c) [97].

Spray coating and inkjet printing have also been applied to accelerate the evaporation of solvent molecules by increasing the substrate temperature and finally obtain a uniform and dense perovskite film. Meanwhile, slot-die deposition [112], spray coating [65, 95], and inkjet printing are low-cost, high-throughput, and substrate-compatible deposition thin-film technologies (Fig. 9a-c). Perovskite crystal grains can grow into larger crystals through re-dissolution, grain-merging, and re-crystallization. The balance of an inward flux $\left(F_{\text {in }}\right)$ and an outward flux $\left(F_{\text {out }}\right)$ can be controlled through deposition parameters such as the solution concentration, solvent mixture, and substrate temperature (Fig. 9d) [95]. Owing to the high sensitivity of perovskite materials in the atmospheric environment, the development of these technologies has been limited. When integrated with hot-casting technology, the sensitivity of the perovskite materials can be improved through the rapid film formation and introduction of all-inorganic components and long alkyl amine chains.

\section{Conclusion and Prospects}

The quality of a perovskite film is a key factor in determining the ultimate performance of PSCs. Hot-casting technology shows excellent device performance and commercialization prospects in the deposition of high-quality perovskite films. The current research status of this technology was comprehensively summarized and discussed in this review. Based on the classical LaMer model, the effects of various depositing parameters on different stages of nucleation and growth of perovskite films were analyzed. The results show that the adjustment of the film formation parameters such as the substrate temperature, thermal annealing, precursor chemistry, and experimental environment can improve the nucleation and crystallization of perovskite, as well as obtain 

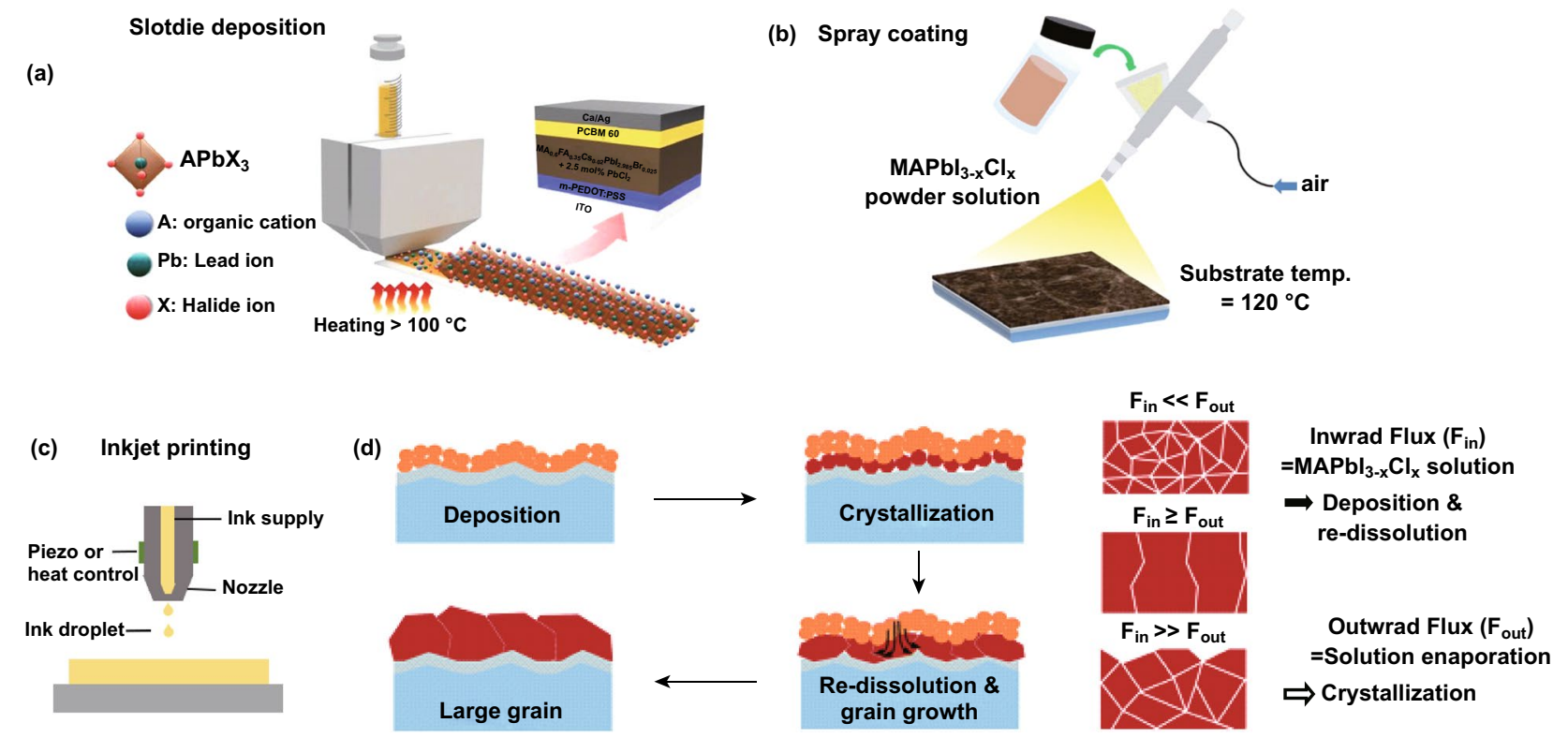

Fig. 9 Common scalable solution deposition methods. a Slot-die deposition [112]. Copyright () 2019 WILEY-VCH Verlag GmbH \& Co. KGaA, Weinheim. b Spray coating [95]. c inkjet printing. d Crystalline grain growth and the morphology of the formed crystalline grains in the perovskite film with respect to the balance between $F_{\text {in }}$ and $F_{\text {out }}$ [95]. Copyright $\odot 2016$ The Royal Society of Chemistry

a higher-quality perovskite film and PSCs with superior performance. In addition, the review highlighted the advantages of hot-casting techniques for the deposition of perovskite films, such as large grain sizes, insensitive thicknesses, and preferred orientations of low-dimensional perovskites. From the perspective of stability, the application of hot-casting technology in inorganic, lead-free, and low-dimensional perovskite films was also summarized. Finally, the prospects of an upscaling of hot-casting technology or integration with other scalable deposition technologies were discussed.

However, there are still some remaining questions about this promising technology that has yet to be fully answered. For example, the chemical reaction of the precursors and the crystallization kinetics process has not been fully disclosed. The interface mechanism of a hot-cast film in contact with a functional layer has not been clearly explained, and the PCE of a device prepared using a hot-casting technique is still lower than that from a conventional solution deposition. The mechanism of water invasion toward hot-cast perovskite surfaces and related stability issues has not been reported in detail in the literature. According to the particular film-forming process and film properties of the hot-casting technology, the following issues should be taken into consideration for the maturity of this technology: The concurrent solvent evaporation and perovskite crystallization over an extremely short period of time (approximately 3-5 s) makes the control of the crystallization a challenge. Adjusting the solvent composition, additives, and solvent engineering will play a role in the proper control of the crystallization. In addition, from a more microscopic perspective, the temperature distribution around the crystal nucleus, grain boundaries, and unit cells during nucleation growth should be analyzed. The mechanism of thermal energy at each stage and the effect of the release of residual thermal energy on the film should be interpreted from a thermodynamic perspective. The integration of a hot-casting technology with other scalable deposition technologies (such as blade coating, spray coating, inkjet printing, screen printing, and slot-die deposition) in the deposition of high-quality perovskite films with a large area, high throughput, and low cost should be highly desirable for future industrial application of this promising technique. Moreover, hot-casting technology has extremely broad prospects in the growth of low-dimensional perovskite films, inorganic perovskite films, and single-crystal growth. In addition, hot-casting technology can be used as an early exploration tool for new materials and structures. This is of great significance for the rapid screening of early research directions. Owing to the rapid and controlled crystallization 
and short film-forming process, we look forward to wide implementation of a hot-casting technique applied to the upscaling deposition of perovskite films and related optoelectronic devices in the near future.

Acknowledgements This work was financially supported by the National Natural Science Foundation of China NSFC (51702038), the Sichuan Science and Technology Program (2020YFG0061), and the Recruitment Program for Young Professionals. L. Ding thanks National Key Research and Development Program of China (2017YFA0206600) and National Natural Science Foundation of China (51773045, 21772030, 51922032, 21961160720) for financial support.

Open Access This article is licensed under a Creative Commons Attribution 4.0 International License, which permits use, sharing, adaptation, distribution and reproduction in any medium or format, as long as you give appropriate credit to the original author(s) and the source, provide a link to the Creative Commons licence, and indicate if changes were made. The images or other third party material in this article are included in the article's Creative Commons licence, unless indicated otherwise in a credit line to the material. If material is not included in the article's Creative Commons licence and your intended use is not permitted by statutory regulation or exceeds the permitted use, you will need to obtain permission directly from the copyright holder. To view a copy of this licence, visit http://creativecommons.org/licenses/by/4.0/.

\section{References}

1. J. Burschka, N. Pellet, S.J. Moon, R. Humphry-Baker, P. Gao, M.K. Nazeeruddin, M. Gratzel, Sequential deposition as a route to high-performance perovskite-sensitized solar cells. Nature 499, 316-319 (2013). https://doi.org/10.1038/nature12340

2. M. Liu, M.B. Johnston, H.J. Snaith, Efficient planar heterojunction perovskite solar cells by vapour deposition. Nature 501, 395-398 (2013). https://doi.org/10.1038/nature12509

3. M.M. Lee, J. Teuscher, T. Miyasaka, T.N. Murakami, H.J. Snaith, Efficient hybrid solar cells based on meso-superstructured organometal halide perovskites. Science 338, 643-647 (2012). https://doi.org/10.1126/science.1228604

4. F. Hao, C.C. Stoumpos, R.P.H. Chang, M.G. Kanatzidis, Anomalous band gap behavior in mixed $\mathrm{Sn}$ and $\mathrm{Pb}$ perovskites enables broadening of absorption spectrum in solar cells. J. Am. Chem. Soc. 136, 8094-8099 (2014). https:// doi.org/10.1021/ja5033259

5. F. Hao, C.C. Stoumpos, P.J. Guo, N.J. Zhou, T.J. Marks, R.P.H. Chang, M.G. Kanatzidis, Solvent-mediated crystallization of $\mathrm{CH}_{3} \mathrm{NH}_{3} \mathrm{SnI}_{3}$ films for heterojunction depleted perovskite solar cells. J. Am. Chem. Soc. 137, 11445-11452 (2015). https://doi.org/10.1021/jacs.5b06658

6. F. Hao, C.C. Stoumpos, D.H. Cao, R.P.H. Chang, M.G. Kanatzidis, Lead-free solid-state organic-inorganic halide perovskite solar cells. Nat. Photonics 8, 489-494 (2014). https://doi.org/10.1038/nphoton.2014.82

7. C.B. Li, A.L. Wang, L.S. Xie, X.Y. Deng, K.J. Liao, J.A. Yang, T.S. Li, F. Hao, Emerging alkali metal ion $\left(\mathrm{Li}^{+}, \mathrm{Na}^{+}\right.$, $\mathrm{K}^{+}$and $\mathrm{Rb}^{+}$) doped perovskite films for efficient solar cells: recent advances and prospects. J. Mater. Chem. A 7, 2415024163 (2019). https://doi.org/10.1039/c9ta08130e

8. L.S. Xie, J.W. Wang, K.J. Liao, J.A. Yang, A.L. Wang et al., Low-cost coenzyme Q10 as an efficient electron transport layer for inverted perovskite solar cells. J. Mater. Chem. A 7, 18626-18633 (2019). https://doi.org/10.1039/c9ta06317j

9. X. Li, M.I. Dar, C.Y. Yi, J.S. Luo, M. Tschumi et al., Improved performance and stability of perovskite solar cells by crystal crosslinking with alkylphosphonic acid omegaammonium chlorides. Nat. Chem. 7, 703-711 (2015). https ://doi.org/10.1038/nchem.2324

10. M.D. Xiao, F.Z. Huang, W.C. Huang, Y. Dkhissi, Y. Zhu et al., A fast deposition-crystallization procedure for highly efficient lead iodide perovskite thin-film solar cells. Angew. Chem. Int. Ed. 53, 9898-9903 (2014). https://doi. org/10.1002/anie.201405334

11. H.C. Liao, P.J. Guo, C.P. Hsu, M. Lin, B.H. Wang et al., Enhanced efficiency of hot-cast large-area planar perovskite solar cells/modules having controlled chloride incorporation. Adv. Energy Mater. 7, 1601660 (2017). https://doi. org/10.1002/aenm.201601660

12. H.B. Zhang, H. Chen, C.C. Stoumpos, J. Ren, Q.Z. Hou et al., Thiazole-induced surface passivation and recrystallization of $\mathrm{CH}_{3} \mathrm{NH}_{3} \mathrm{PbI}_{3}$ films for perovskite solar cells with ultrahigh fill factors. ACS Appl. Mater. Interfaces 10, 42436-42443 (2018). https://doi.org/10.1021/acsami.8b16124

13. W.S. Yang, J.H. Noh, N.J. Jeon, Y.C. Kim, S. Ryu, J. Seo, S.I. Seok, High-performance photovoltaic perovskite layers fabricated through intramolecular exchange. Science 348, 1234-1237 (2015). https://doi.org/10.1126/science.aaa9272

14. J.H. Im, I.H. Jang, N. Pellet, M. Gratzel, N.G. Park, Growth of $\mathrm{CH}_{3} \mathrm{NH}_{3} \mathrm{PbI}_{3}$ cuboids with controlled size for high-efficiency perovskite solar cells. Nat. Nanotechnol. 9, 927-932 (2014). https://doi.org/10.1038/nnano.2014.181

15. C.H. Chiang, Z.L. Tseng, C.G. Wu, Planar heterojunction perovskite/PC ${ }_{71} \mathrm{BM}$ solar cells with enhanced open-circuit voltage via a(2/1)-step spin-coating process. J. Mater. Chem. A 2, 15897-15903 (2014). https://doi.org/10.1039/c4ta03674c

16. Q. Chen, H. Zhou, Z. Hong, S. Luo, H.S. Duan et al., Planar heterojunction perovskite solar cells via vapor-assisted solution process. J. Am. Chem. Soc. 136, 622-625 (2014). https ://doi.org/10.1021/ja411509g

17. C.M.M. Soe, W.Y. Nie, C.C. Stoumpos, H. Tsai, J.C. Blancon et al., Understanding film formation morphology and orientation in high member 2D Ruddlesden-Popper perovskites for high-efficiency solar cells. Adv. Energy Mater. 8, 1700979 (2018). https://doi.org/10.1002/aenm.201700979

18. Y.N. Chen, Y. Sun, J.J. Peng, W. Zhang, X.J. Su et al., Tailoring organic cation of 2D air-stable organometal halide perovskites for highly efficient planar solar cells. Adv. 
Energy Mater. 7, 1700162 (2017). https://doi.org/10.1002/ aenm.201700162

19. W.Y. Nie, H.H. Tsai, R. Asadpour, J.C. Blancon, A.J. Neukirch et al., High-efficiency solution-processed perovskite solar cells with millimeter-scale grains. Science 347, 522525 (2015). https://doi.org/10.1126/science.aaa0472

20. C.Y. Chang, Y.C. Huang, C.S. Tsao, W.F. Su, Formation mechanism and control of perovskite films from solution to crystalline phase studied by in situ synchrotron scattering. ACS Appl. Mater. Interfaces 8, 26712-26721 (2016). https ://doi.org/10.1021/acsami.6b07468

21. N. Faibut, P. Kamlangwan, W. Jarernboon, P. Klangtakai, V. Harnchana, V. Amornkitbamrung, $\mathrm{CH}_{3} \mathrm{NH}_{3} \mathrm{PbI}_{3}$ thin films prepared by hot-casting technique in the air: growth mechanism, trap states and relating solar cells. Jpn. J. Appl. Phys. 58, 8-17 (2019). https://doi.org/10.7567/1347-4065/ab253 5

22. J.J. van Franeker, K.H. Hendriks, B.J. Bruijnaers, M. Verhoeven, M.M. Wienk, R.A.J. Janssen, Monitoring thermal annealing of perovskite solar cells with in situ photoluminescence. Adv. Energy Mater. 7, 1601822 (2017). https://doi. org/10.1002/aenm.201601822

23. C.C. Stoumpos, C.M.M. Soe, H. Tsai, W.Y. Nie, J.C. Blancon et al., High members of the 2D ruddlesden-popper halide perovskites: synthesis, optical properties, and solar cells of $\left(\mathrm{CH}_{3}\left(\mathrm{CH}_{2}\right)_{3} \mathrm{NH}_{3}\right)_{2}\left(\mathrm{CH}_{3} \mathrm{NH}_{3}\right)_{4} \mathrm{~Pb}_{5} \mathrm{I}_{16}$. Chem 2, 427-440 (2017). https://doi.org/10.1016/j.chempr.2017.02.004

24. Y. Lin, Y. Fang, J. Zhao, Y. Shao, S.J. Stuard et al., Unveiling the operation mechanism of layered perovskite solar cells. Nat. Commun. 10, 1008 (2019). https://doi.org/10.1038/ s41467-019-08958-9

25. R.T. Dong, C.Y. Lan, X.W. Xu, X.G. Liang, X.Y. Hu et al., Novel series of quasi-2D Ruddlesden-Popper perovskites based on short-chained spacer cation for enhanced photodetection. ACS Appl. Mater. Interfaces 10, 19019-19026 (2018). https://doi.org/10.1021/acsami.8b03517

26. Z.A. Peng, X.G. Peng, Nearly monodisperse and shape-controlled CdSe nanocrystals via alternative routes: nucleation and growth. J. Am. Chem. Soc. 124, 3343-3353 (2002). https ://doi.org/10.1021/ja0173167

27. E.E. Finney, R.G. Finke, Nanocluster nucleation and growth kinetic and mechanistic studies: a review emphasizing transition-metal nanoclusters. J. Colloid Interface Sci. 317, 351-374 (2008). https://doi.org/10.1016/j.jcis.2007.05.092

28. C.D. Donega, P. Liljeroth, D. Vanmaekelbergh, Physicochemical evaluation of the hot-injection method, a synthesis route for monodisperse nanocrystals. Small 1, 1152-1162 (2005). https://doi.org/10.1002/smll.200500239

29. V.K. LaMer, R.H. Dinegar, Theory, production and mechanism of formation of mono-dispersed hydrosols. J. Am. Chem. Soc. 72, 4847-4854 (1950). https://doi.org/10.1021/ ja01167a001

30. J.A. Blackman, A. Wilding, Scaling theory of island growth in thin-films. EuroPhys. Lett. 16, 115-120 (1991). https:// doi.org/10.1209/0295-5075/16/1/020
31. H.Z. Yu, C.V. Thompson, Grain growth and complex stress evolution during Volmer-Weber growth of polycrystalline thin films. Acta Mater. 67, 189-198 (2014). https://doi. org/10.1016/j.actamat.2013.12.031

32. A. Toramaru, Model of nucleation and growth of crystals in cooling magmas. Contrib. Mineral. Petrol. 108, 106-117 (1991). https://doi.org/10.1007/bf00307330

33. C. Friesen, C.V. Thompson, Reversible stress relaxation during precoalescence interruptions of Volmer-Weber thin film growth. Phys. Rev. Lett. 89, 126103 (2002). https://doi. org/10.1103/PhysRevLett.89.126103

34. C. Liu, Y. Yang, X. Xia, Y. Ding, Z. Arain et al., Soft template-controlled growth of high-quality $\mathrm{CsPbI}_{3}$ films for efficient and stable solar cells. Adv. Energy Mater. 10, 1903751 (2020). https://doi.org/10.1002/aenm.201903751

35. Y. Ding, I.S. Yang, Z.Q. Li, X. Xia, W.I. Lee et al., Nanoporous $\mathrm{TiO}_{2}$ spheres with tailored textural properties: controllable synthesis, formation mechanism, and photochemical applications. Prog. Mater. Sci. 109, 100620 (2020). https ://doi.org/10.1016/j.pmatsci.2019.100620

36. M. Anaya, J.F. Galisteo-Lopez, M.E. Calvo, C. Lopez, H. Miguez, Photophysical analysis of the formation of organicinorganic trihalide perovskite films: identification and characterization of crystal nucleation and growth. J. Phys. Chem. C 120, 3071-3076 (2016). https://doi.org/10.1021/ acs.jpcc.6b00398

37. Y.C. Zheng, S. Yang, X. Chen, Y. Chen, Y. Hou, H.G. Yang, Thermal-induced Volmer-Weber growth behavior for planar heterojunction perovskites solar cells. Chem. Mater. 27, 5116-5121 (2015). https://doi.org/10.1021/acs.chemm ater.5b01924

38. C.Y. Xue, Y.T. Shi, C.Y. Zhang, Y.P. Lv, Y.L. Feng et al., Favorable growth of well-crystallized layered hybrid perovskite by combination of thermal and solvent assistance. J. Power Sources 422, 156-162 (2019). https://doi. org/10.1016/j.jpowsour.2019.03.037

39. N.J. Zadeh, M.B. Zarandi, M.R. Nateghi, Effect of crystallization strategies on $\mathrm{CH}_{3} \mathrm{NH}_{3} \mathrm{PbI}_{3}$ perovskite layer deposited by spin coating method: dependence of photovoltaic performance on morphology evolution. Thin Solid Films 660, 65-74 (2018). https://doi.org/10.1016/j.tsf.2018.03.038

40. S. Sanchez, N. Christoph, B. Grobety, N. Phung, U. Steiner, M. Saliba, A. Abate, Efficient and stable inorganic perovskite solar cells manufactured by pulsed flash infrared annealing. Adv. Energy Mater. 8, 1802060 (2018). https:// doi.org/10.1002/aenm.201802060

41. S. Sanchez, X. Hua, N. Phung, U. Steiner, A. Abate, Flash infrared annealing for antisolvent-free highly efficient perovskite solar cells. Adv. Energy Mater. 8, 1702915 (2018). https://doi.org/10.1002/aenm.201702915

42. X.L. Li, L.H. Li, Z.H. Ma, J.L. Huang, F.Z. Ren, Low-cost synthesis, fluorescent properties, growth mechanism and structure of $\mathrm{CH}_{3} \mathrm{NH}_{3} \mathrm{PbI}_{3}$ with millimeter grains. Optik 142, 293-300 (2017). https://doi.org/10.1016/j.ijleo.2017.05.107

43. D.N. Feria, C.Y. Chang, K.P.O. Mahesh, C.L. Hsu, Y.C. Chao, Perovskite solar cells based on a perovskite film with 
improved film coverage. Synthetic Met. 260, 116283 (2020). https://doi.org/10.1016/j.synthmet.2019.116283

44. A. Dualeh, N. Tetreault, T. Moehl, P. Gao, M.K. Nazeeruddin, M. Gratzel, Effect of annealing temperature on film morphology of organic-inorganic hybrid pervoskite solid-state solar cells. Adv. Funct. Mater. 24, 3250-3258 (2014). https://doi. org/10.1002/adfm.201304022

45. S.A. Kulkarni, T. Baikie, P.P. Boix, N. Yantara, N. Mathews, S. Mhaisalkar, Band-gap tuning of lead halide perovskites using a sequential deposition process. J. Mater. Chem. A 2, 9221-9225 (2014). https://doi.org/10.1039/c4ta00435c

46. H. Tsai, W.Y. Nie, Y.H. Lin, J.C. Blancon, S. Tretiak et al., Effect of precursor solution aging on the crystallinity and photovoltaic performance of perovskite solar cells. Adv. Energy Mater. 7, 1602159 (2017). https://doi.org/10.1002/ aenm.201602159

47. Y.H. Seo, E.C. Kim, S.P. Cho, S.S. Kim, S.I. Na, High-performance planar perovskite solar cells: influence of solvent upon performance. Appl. Mater. Today 9, 598-604 (2017). https://doi.org/10.1016/j.apmt.2017.11.003

48. Z. Arain, C. Liu, Y. Yang, M. Mateen, Y.K. Ren et al., Elucidating the dynamics of solvent engineering for perovskite solar cells. Sci. China-Mater. 62, 161-172 (2019). https://doi. org/10.1007/s40843-018-9336-1

49. B. Li, D. Binks, G.Z. Cao, J.J. Tian, Engineering halide perovskite crystals through precursor chemistry. Small 15, 1903613 (2019). https://doi.org/10.1002/smll.201903613

50. Z.H. Liu, J.N. Hu, H.Y. Jiao, L. Li, G.H.J. Zheng et al., Chemical reduction of intrinsic defects in thicker heterojunction planar perovskite solar cells. Adv. Mater. 29, 1606774 (2017). https://doi.org/10.1002/adma.201606774

51. C.H. Chiang, J.W. Lin, C.G. Wu, One-step fabrication of a mixed-halide perovskite film for a high-efficiency inverted solar cell and module. J. Mater. Chem. A 4, 13525-13533 (2016). https://doi.org/10.1039/c6ta05209f

52. K.J. Liao, J.A. Yang, C.B. Li, T.S. Li, F. Hao, Off-stoichiometric methylammonium iodide passivated large-grain perovskite film in ambient air for efficient inverted solar cells. ACS Appl. Mater. Interfaces 11, 39882-39889 (2019). https ://doi.org/10.1021/acsami.9b12829

53. J.H. Chen, L.J. Zuo, Y.Z. Zhang, X.M. Lian, W.F. Fu et al., High-performance thickness insensitive perovskite solar cells with enhanced moisture stability. Adv. Energy Mater. 8, 1800438 (2018). https://doi.org/10.1002/aenm.201800438

54. T.H. Liu, Y.Y. Zhou, Q. Hu, K. Chen, Y.F. Zhang et al., Fabrication of compact and stable perovskite films with optimized precursor composition in the fast-growing procedure. Sci. China-Mater. 60, 608-616 (2017). https://doi.org/10.1007/ s40843-017-9044-y

55. S.W. Wang, L.J. Wang, L. Zhang, L. Chang, L. Wang, J.L. Wang, Construction of high performance $\mathrm{CH}_{3} \mathrm{NH}_{3} \mathrm{PbI}_{3}$-based solar cells by hot-casting technique. Sol. Energy Mater. Sol. Cells 163, 120-124 (2017). https://doi.org/10.1016/j.solma t.2017.01.009

56. M.A. Afroz, R.K. Gupta, R. Garai, M. Hossain, S.P. Tripathi, P.K. Iyer, Crystallization and grain growth regulation through
Lewis acid-base adduct formation in hot cast perovskitebased solar cells. Org. Electron. 74, 172-178 (2019). https:// doi.org/10.1016/j.orgel.2019.07.007

57. G.S. Shin, W.G. Choi, S. Na, F.P. Gokdemir, T. Moon, Lead acetate based hybrid perovskite through hot casting for planar heterojunction solar cells. Electron. Mater. Lett. 14, 155-160 (2018). https://doi.org/10.1007/s13391-018-0042-1

58. L.F. Chao, Y.D. Xia, B.X. Li, G.C. Xing, Y.H. Chen, W. Huang, Room-temperature molten salt for facile fabrication of efficient and stable perovskite solar cells in ambient air. Chem 5, 995-1006 (2019). https://doi.org/10.1016/j.chemp r.2019.02.025

59. Y. Ding, J. Chen, H. Chen, Y.M. Yang, J. Xu, J.X. Yao, Atmosphere dependent gas-solid reaction for high-quality MAPbBr 3 perovskite solar cells. Appl. Surf. Sci. 510, 145356 (2020). https://doi.org/10.1016/j.apsusc.2020.145356

60. J.A. Christians, P.A.M. Herrera, P.V. Kamat, Transformation of the excited state and photovoltaic efficiency of $\mathrm{CH}_{3} \mathrm{NH}_{3} \mathrm{PbI}_{3}$ perovskite upon controlled exposure to humidified air. J. Am. Chem. Soc. 137, 1530-1538 (2015). https:// doi.org/10.1021/ja511132a

61. Y. Han, S. Meyer, Y. Dkhissi, K. Weber, J.M. Pringle, U. Bach, L. Spiccia, Y.B. Cheng, Degradation observations of encapsulated planar $\mathrm{CH}_{3} \mathrm{NH}_{3} \mathrm{PbI}_{3}$ perovskite solar cells at high temperatures and humidity. J. Mater. Chem. A 3, 81398147 (2015). https://doi.org/10.1039/c5ta00358j

62. I.C. Smith, E.T. Hoke, D. Solis-Ibarra, M.D. McGehee, H.I. Karunadasa, A layered hybrid perovskite solar-cell absorber with enhanced moisture stability. Angew. Chem. Int. Ed. 53, 11232-11235 (2014). https://doi.org/10.1002/anie.20140 6466

63. K.A. Bush, A.F. Palmstrom, Z.S.J. Yu, M. Boccard, R. Cheacharoen et al., 23.6\%-efficient monolithic perovskite/silicon tandem solar cells with improved stability. Nat. Energy 2, 17009 (2017). https://doi.org/10.1038/nenergy.2017.9

64. B.L. Lei, V.O. Eze, T. Mori, High-performance $\mathrm{CH}_{3} \mathrm{NH}_{3} \mathrm{PbI}_{3}$ perovskite solar cells fabricated under ambient conditions with high relative humidity. Jpn. J. Appl. Phys. 54, 100305 (2015). https://doi.org/10.7567/jjap.54.100305

65. M. Habibi, M.R. Ahmadian-Yazdi, M. Eslamian, Optimization of spray coating for the fabrication of sequentially deposited planar perovskite solar cells. J. Photonics Energy 7, 022003 (2017). https://doi.org/10.1117/1.Jpe.7.022003

66. J.A. Aguiar, N.R. Alkurd, S. Wozny, M.K. Patel, M.J. Yang et al., In situ investigation of halide incorporation into perovskite solar cells. MRS Commun. 7, 575-582 (2017). https ://doi.org/10.1557/mrc.2017.52

67. K.Q. Huang, C.H. Wang, C.J. Zhang, S.C. Tong, H.Y. Li et al., Efficient and stable planar heterojunction perovskite solar cells fabricated under ambient conditions with high humidity. Org. Electron. 55, 140-145 (2018). https://doi. org/10.1016/j.orgel.2018.01.029

68. J.A. Yang, T.X. Qin, L.S. Xie, K.J. Liao, T.S. Li, F. Hao, Methylamine-induced defect-healing and cationic substitution: a new method for low-defect perovskite thin films and 
solar cells. J. Mater. Chem. C 7, 10724-10742 (2019). https ://doi.org/10.1039/c9tc03490k

69. C.B. Li, A.L. Wang, L.S. Xie, X.Y. Deng, K.J. Liao, J.A. Yang, Y. Xiang, F. Hao, Secondary lateral growth of $\mathrm{MAPbI}_{3}$ grains for the fabrication of efficient perovskite solar cells. J. Mater. Chem. C 8, 3217-3225 (2020). https://doi. org/10.1039/c9tc06293a

70. G. Wang, C. Liu, W. Kong, H. Chen, D. Li et al., Liberating researchers from the glovebox: a universal thermal radiation protocol toward efficient fully air-processed perovskite solar cells. Sol. RRL 3, 1800324 (2019). https://doi.org/10.1002/ solr.201800324

71. Y. Liu, Y. Zhang, Z. Yang, H. Ye, J. Feng et al., Multi-inch single-crystalline perovskite membrane for high-detectivity flexible photosensors. Nat. Commun. 9, 5302 (2018). https:// doi.org/10.1038/s41467-018-07440-2

72. Y. Liu, Y. Zhang, K. Zhao, Z. Yang, J. Feng et al., A $1300 \mathrm{~mm}^{2}$ ultrahigh-performance digital imaging assembly using high-quality perovskite single crystals. Adv. Mater. 30, 1707314 (2018). https://doi.org/10.1002/adma.201707314

73. Z. Yu, L. Zhang, S. Tian, F. Zhang, B. Zhang et al., Hotsubstrate deposition of hole- and electron-transport layers for enhanced performance in perovskite solar cells. Adv. Energy Mater. 8, 1701659 (2018). https://doi.org/10.1002/ aenm.201701659

74. A. Wang, Z. Cao, J. Wang, S. Wang, C. Li et al., Vacancy defect modulation in hot-casted $\mathrm{NiO}_{x}$ film for efficient inverted planar perovskite solar cells. J. Energy Chem. 48, 426-434 (2020). https://doi.org/10.1016/j.jeche m.2020.02.034

75. S. Bag, M.F. Durstock, Large perovskite grain growth in lowtemperature solution-processed planar $p-i-n$ solar cells by sodium addition. ACS Appl. Mater. Interfaces 8, 5053-5057 (2016). https://doi.org/10.1021/acsami.5b11494

76. J.W. Lee, H.S. Kim, N.G. Park, Lewis acid-base adduct approach for high efficiency perovskite solar cells. Acc. Chem. Res. 49, 311-319 (2016). https://doi.org/10.1021/acs. accounts. 5 b00440

77. E. Horvath, M. Spina, Z. Szekrenyes, K. Kamaras, R. Gaal, D. Gachet, L. Forro, Nanowires of methylammonium lead iodide $\mathrm{CH}_{3} \mathrm{NH}_{3} \mathrm{Pbl}_{3}$ prepared by low temperature solutionmediated crystallization. Nano Lett. 14, 6761-6766 (2014). https://doi.org/10.1021/n15020684

78. S. Wang, Z.R. Ma, B.B. Liu, W.C. Wu, Y. Zhu, R.X. Ma, C.Y. Wang, High-performance perovskite solar cells with large grain-size obtained by using the Lewis acid-base adduct of thiourea. Sol. RRL 2, 1800034 (2018). https://doi. org/10.1002/solr.201800034

79. F.Z. Huang, A.R. Pascoe, W.Q. Wu, Z.L. Ku, Y. Peng et al., Effect of the microstructure of the functional layers on the efficiency of perovskite solar cells. Adv. Mater. 29, 1601715 (2017). https://doi.org/10.1002/adma.201601715

80. A.R. Pascoe, S. Meyer, W.C. Huang, W. Li, I. Benesperi et al., Enhancing the optoelectronic performance of perovskite solar cells via a textured $\mathrm{CH}_{3} \mathrm{NH}_{3} \mathrm{PbI}_{3}$ morphology.
Adv. Funct. Mater. 26, 1278-1285 (2016). https://doi. org/10.1002/adfm.201504190

81. L.A. Muscarella, E.M. Hutter, S. Sanchez, C.D. Dieleman, T.J. Savenije et al., Crystal orientation and grain size: do they determine optoelectronic properties of $\mathrm{MAPbI}_{3}$ perovskite? J. Phys. Chem. Lett. 10, 6010-6018 (2019). https ://doi.org/10.1021/acs.jpclett.9b02757

82. A. Krishna, S. Gottis, M.K. Nazeeruddin, F. Sauvage, Mixed dimensional 2D/3D hybrid perovskite absorbers: the future of perovskite solar cells? Adv. Funct. Mater. 29, 1806482 (2019). https://doi.org/10.1002/adfm.201806482

83. S. Chen, G.Q. Shi, Two-dimensional materials for halide perovskite-based optoelectronic devices. Adv. Mater. 29, 1605448 (2017). https://doi.org/10.1002/adma.201605448

84. L.T. Dou, A.B. Wong, Y. Yu, M.L. Lai, N. Kornienko et al., Atomically thin two-dimensional organic-inorganic hybrid perovskites. Science 349, 1518-1521 (2015). https://doi. org/10.1126/science.aac7660

85. L. Pedesseau, D. Sapori, B. Traore, R. Robles, H.H. Fang et al., Advances and promises of layered halide hybrid perovskite semiconductors. ACS Nano 10, 9776-9786 (2016). https://doi.org/10.1021/acsnano.6b05944

86. G.B. Wu, J.Y. Zhou, J.Q. Zhang, R. Meng, B.X. Wang et al., Management of the crystallization in two-dimensional perovskite solar cells with enhanced efficiency within a wide temperature range and high stability. Nano Energy 58, 706714 (2019). https://doi.org/10.1016/j.nanoen.2019.02.002

87. X. Zhang, R. Munir, Z. Xu, Y. Liu, H. Tsai et al., Phase transition control for high performance Ruddlesden-Popper perovskite solar cells. Adv. Mater. 30, 1707166 (2018). https:// doi.org/10.1002/adma.201707166

88. Z. Wang, X.D. Liu, Y.W. Lin, Y.J. Liao, Q. Wei et al., Hotsubstrate deposition of all-inorganic perovskite films for lowtemperature processed high-efficiency solar cells. J. Mater. Chem. A 7, 2773-2779 (2019). https://doi.org/10.1039/c8ta0 $9855 \mathrm{~g}$

89. J.P. Correa-Baena, M. Saliba, T. Buonassisi, M. Gratzel, A. Abate, W. Tress, A. Hagfeldt, Promises and challenges of perovskite solar cells. Science 358, 739-744 (2017). https:// doi.org/10.1126/science.aam6323

90. O. Granas, D. Vinichenko, E. Kaxiras, Establishing the limits of efficiency of perovskite solar cells from first principles modeling. Sci. Rep. 6, 36108 (2016). https://doi.org/10.1038/ srep36108

91. H.H. Tsai, W.Y. Nie, J.C. Blancon, C.C.S. Toumpos, R. Asadpour et al., High-efficiency two-dimensional RuddlesdenPopper perovskite solar cells. Nature 536, 312-316 (2016). https://doi.org/10.1038/nature18306

92. B. Ghosh, B. Wu, X.T. Guo, P.C. Harikesh, R.A. John et al., Superior performance of silver bismuth iodide photovoltaics fabricated via dynamic hot-casting method under ambient conditions. Adv. Energy Mater. 8, 1802051 (2018). https:// doi.org/10.1002/aenm.201802051

93. W.Z. Li, J.L. Li, L.D. Wang, G.D. Niu, R. Gao, Y. Qiu, Post modification of perovskite sensitized solar cells by aluminum 
oxide for enhanced performance. J. Mater. Chem. A 1, 11735-11740 (2013). https://doi.org/10.1039/c3ta12240a

94. K.C. Hsiao, M.H. Jao, B.T. Li, T.H. Lin, S.H.C. Liao, M.C. $\mathrm{Wu}$, W.F. Su, Enhancing efficiency and stability of hot casting $p-i-n$ perovskite solar cell via dipolar ion passivation. ACS Appl. Mater. Interfaces 2, 4821-4832 (2019). https:// doi.org/10.1021/acsaem.9b00486

95. J.H. Heo, M.H. Lee, M.H. Jang, S.H. Im, Highly efficient $\mathrm{CH}_{3} \mathrm{NH}_{3} \mathrm{PbI}_{3-x} \mathrm{Cl}_{x}$ mixed halide perovskite solar cells prepared by re-dissolution and crystal grain growth via spray coating. J. Mater. Chem. A 4, 17636-17642 (2016). https:// doi.org/10.1039/c6ta06718b

96. S. Tang, Y. Deng, X. Zheng, Y. Bai, Y. Fang et al., Composition engineering in doctor-blading of perovskite solar cells. Adv. Energy Mater. 7, 1700302 (2017). https://doi. org/10.1002/aenm.201700302

97. J. Li, R. Munir, Y. Fan, T. Niu, Y. Liu et al., Phase transition control for high-performance blade-coated perovskite solar cells. Joule 2, 1313-1330 (2018). https://doi.org/10.1016/j. joule.2018.04.011

98. Y.Y. Dang, J. Wei, X.L. Liu, X. Wang, K. Xu et al., Layered hybrid perovskite solar cells based on single-crystalline precursor solutions with superior reproducibility. Sustain. Energy Fuels 2, 2237-2243 (2018). https://doi.org/10.1039/ c8se00213d

99. W. Zhao, X. Gan, L. Ke, L. Guo, H. Liu, 2D multilayered perovskites based on 4-chlorophenylethylamine for solar cell application. Sol. Energy 196, 1-9 (2020). https://doi. org/10.1016/j.solener.2019.12.021

100. X. Zhu, Z. Xu, S. Zuo, J. Feng, Z. Wang et al., Vapor-fumigation for record efficiency two-dimensional perovskite solar cells with superior stability. Energy Environ. Sci. 11, 33493357 (2018). https://doi.org/10.1039/c8ee02284d

101. Y. Zhang, P. Wang, M.C. Tang, D. Barrit, W. Ke et al., Dynamical transformation of two-dimensional perovskites with alternating cations in the interlayer space for high-performance photovoltaics. J. Am. Chem. Soc. 141, 2684-2694 (2019). https://doi.org/10.1021/jacs.8b13104

102. Y. Zhou, X. Yin, Q. Luo, X. Zhao, D. Zhou et al., Efficiently improving the stability of inverted perovskite solar cells by employing polyethylenimine-modified carbon nanotubes as electrodes. ACS Appl. Mater. Interfaces 10, 31384-31393 (2018). https://doi.org/10.1021/acsami.8b10253

103. Q. Zhang, H. Nan, Y.Y. Zhou, Y.C. Gu, M.Q. Tai et al., In situ growth of alpha-CsPbI ${ }_{3}$ perovskite nanocrystals on the surface of reduced graphene oxide with enhanced stability and carrier transport quality. J. Mater. Chem. C 7, 6795-6804 (2019). https://doi.org/10.1039/c9tc01012b

104. Q. Luo, H. Ma, F. Hao, Q.Z. Hou, J. Ren et al., Carbon nanotube based inverted flexible perovskite solar cells with allinorganic charge contacts. Adv. Funct. Mater. 27, 1703068 (2017). https://doi.org/10.1002/adfm.201703068

105. Y. Lin, Y. Bai, Y. Fang, Z. Chen, S. Yang et al., Enhanced thermal stability in perovskite solar cells by assembling 2D/3D stacking structures. J. Phys. Chem. Lett. 9, 654-658 (2018). https://doi.org/10.1021/acs.jpclett.7b02679

106. L. Li, N. Zhou, Q. Chen, Q. Shang, Q. Zhang, X. Wang, H. Zhou, Unraveling the growth of hierarchical quasi-2D/3D perovskite and carrier dynamics. J. Phys. Chem. Lett. 9, 11241132 (2018). https://doi.org/10.1021/acs.jpclett.7b03294

107. Y. Fan, J. Fang, X. Chang, M.C. Tang, D. Barrit et al., Scalable ambient fabrication of high-performance $\mathrm{CsPbI}_{2} \mathrm{Br}$ solar cells. Joule 3, 2485-2502 (2019). https://doi.org/10.1016/j. joule.2019.07.015

108. D.B. Kim, S. Lee, C.H. Jang, J.H. Park, A.Y. Lee, M.H. Song, Uniform and large-area cesium-based quasi-2D perovskite light-emitting diodes using hot-casting method. Adv. Mater. Interfaces 7, 1902158 (2020). https://doi.org/10.1002/ admi.201902158

109. A.T. Mallajosyula, K. Fernando, S. Bhatt, A. Singh, B.W. Alphenaar et al., Large-area hysteresis-free perovskite solar cells via temperature controlled doctor blading under ambient environment. Appl. Mater. Today 3, 96-102 (2016). https:// doi.org/10.1016/j.apmt.2016.03.002

110. Y. Deng, Q. Wang, Y. Yuan, J. Huang, Vividly colorful hybrid perovskite solar cells by doctor-blade coating with perovskite photonic nanostructures. Mater. Horiz. 2, 578-583 (2015). https://doi.org/10.1039/c5mh00126a

111. Y. Deng, X. Zheng, Y. Bai, Q. Wang, J. Zhao, J. Huang, Surfactant-controlled ink drying enables high-speed deposition of perovskite films for efficient photovoltaic modules. Nat. Energy 3, 560-566 (2018). https://doi.org/10.1038/s4156 0-018-0153-9

112. J.E. Kim, S.S. Kim, C. Zuo, M. Gao, D. Vak, D.Y. Kim, Humidity-tolerant roll-to-roll fabrication of perovskite solar cells via polymer-additive-assisted hot slot die deposition. Adv. Funct. Mater. 29, 1809194 (2019). https://doi. org/10.1002/adfm.201809194 